\title{
A GIS-Based Information System for Predicting Impacts from Coastal Storms- The Coastal Impact Assessment Tool (CIAT), Version 1.0, User's Manual
}

By Brian H. Bossak, Robert A. Morton, and Asbury H. Sallenger, Jr.

Open-File Report 2005-1260 



\section{A GIS-Based Information System for Predicting Impacts from Coastal Storms- The Coastal Impact Assessment Tool (CIAT), Version 1.0, User's Manual}

By Brian H. Bossak, Robert A. Morton, and Asbury H. Sallenger, Jr.

Open-File Report 2005-1260 



\section{Contents}

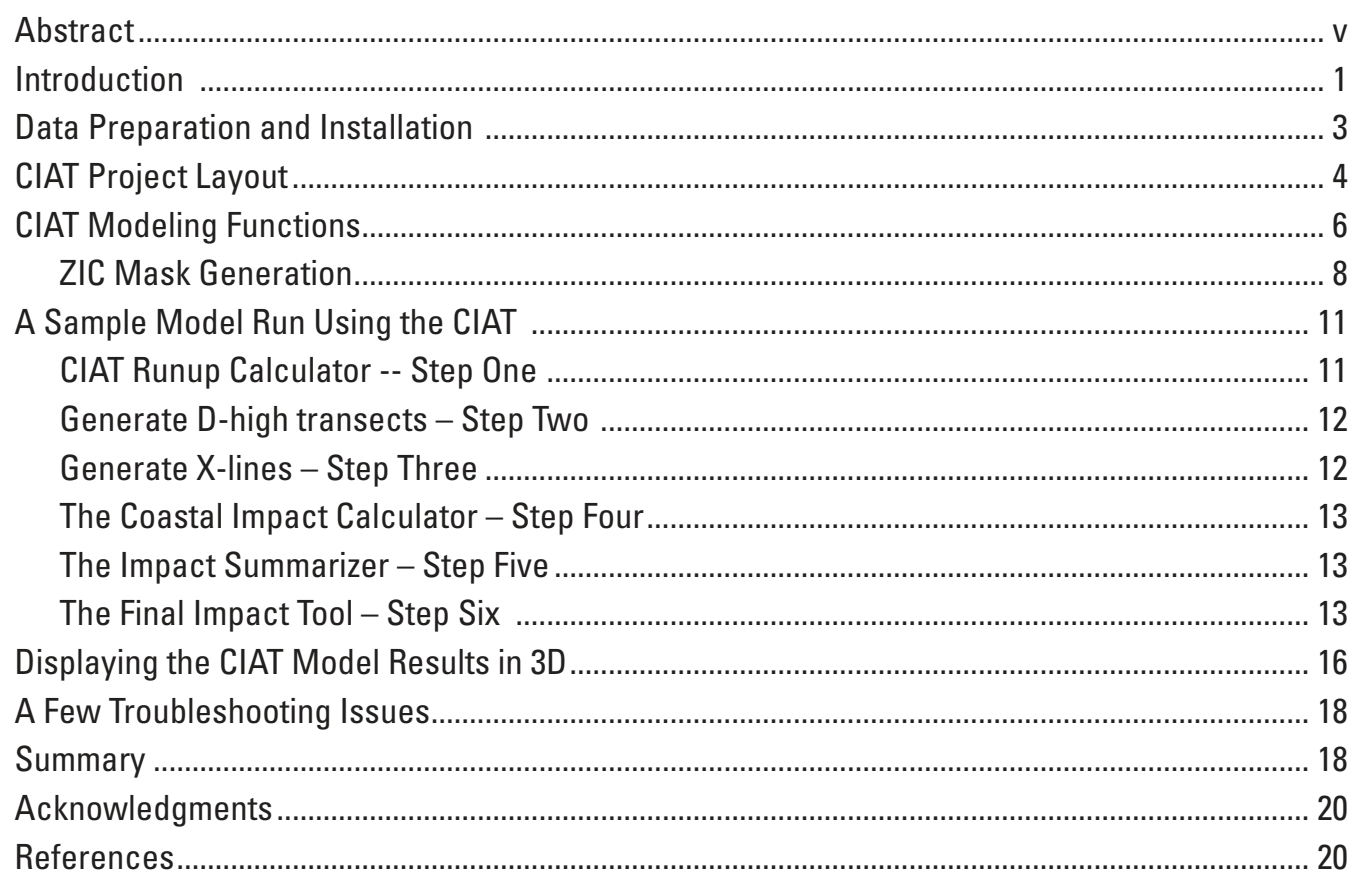




\begin{abstract}
The Coastal Impact Assessment Tool (CIAT), Version 1.0, is a new GIS-based set of digital tools designed for use by coastal managers, scientists, emergency managers, and eventually, the general public, to predict the impacts to primary dunes from coastal storms such as hurricanes and nor'easters. The tool incorporates previously published coastal impact prediction methodology, and requires minimal user input. The model utilizes parameters such as beach slope, wave height, wave period, and tide/storm surge values in its incorporated wave runup models, and uses raster-based dune crest elevations. The CIAT v1.0 can incorporate the latest LIDAR-derived data, resulting in accuracy improvements over aerial-photography-derived topographic elevations. This document describes the structure of the CIAT v1.0, its practical usage, visualization capabilities, troubleshooting tips, and a description of improvements to the model that may be available in future versions.
\end{abstract}




\title{
A GIS-Based Information System for Predicting Impacts from Coastal Storms - The Coastal Impact Assessment Tool (CIAT), Version 1.0, User's Manual
}

\author{
By Brian H. Bossak, Robert A. Morton, and Asbury H. Sallenger, Jr.
}

\section{Introduction}

Coastal storms on the Atlantic coast include tropical cyclones, such as hurricanes, and extratropical systems such as nor'easters. These storms are responsible for damage to structures, dune erosion, and shoreline reshaping along coastal regions. Although coastal damage from tropical cyclones is widely publicized and can be extreme (as in Hurricane Camille of 1969 and Hurricane Ivan of 2004), the spatial extent of the most serious damage is relatively small. In contrast, nor' easters, such as the 1962 Ash Wednesday and 1991 All Hallows Eve storms, are capable of extensive coastal damage over much larger sections of coastline than tropical cyclones.

The Coastal Impact Assessment Tool (CIAT) stems from research projects aimed at predicting the effect of coastal storms on beaches and dunes. The U.S. Geological Survey has long been working on the development of coastal change prediction algorithms; the CIAT incorporates some of these models in a GIS environment. Some of the many benefits of GIS for coastal research purposes include simplified data access, ease of editing and updating, and on-the-fly visualization of coastal hazards. A demonstration pilot project was designed to test the utility of the CIAT and to predict coastal impact by including multiple empirical storm parameters. The pilot project focused on Assateague Island, Maryland/Virginia (Figure 1). Although Assateague Island is the only location that has been tested with data specifically processed for CIAT usage, the CIAT was designed to work with any location that has properly formatted data files.

Assateague Island was selected as the test site partly because it has near-full-island EAARL coverage. The EAARL LIDAR dataset (from surveys flown in 2002) is generated from an experimental NASA airborne sensor that is capable of detecting second returns from the laser pulse, and it therefore provides the most accurate topographic information available for the island $( \pm 15 \mathrm{~cm}$ vertical accuracy). The LIDAR dataset for Assateague was preceded by near-full-island Airborne Topographic Mapper (ATM) LIDAR surveys (based on the first return of the laser pulse) that were flown in 1997 and 1998.
Moreover, much of the dune structure on the island allows for the selection of dune crests/bases, and the Sallenger Storm Impact Scale (SSIS) can then be used to characterize coastal changes following storms (Sallenger, 2000). The CIAT makes use of a coastal impact prediction methodology that utilizes gridded elevation and beach slope datasets derived from LIDAR surveys.

The end result of the project is a GIS-based tool that predicts Sallenger Storm Impact Scales based on input parameters such as wave height, period, and projected storm surge/tidal records. The tool also incorporates a capability to access multiple data layers rapidly, including USGS Digital Elevation Models (DEMs), Digital Raster Graphics (DRGs) - digitized USGS topographic maps, and aerial photography (both newer and historical). Data pertaining to the historical storm of record for any location, which for Assateague Island is the Ash Wednesday storm of March, 1962 (Morton et al., 2003), can also be added to the project. In addition to using the model for prediction purposes based on current and future LIDARbased data, hindcasts were conducted for model validation purposes on the ATM LIDAR data for Assateague Island that were acquired before and after two strong nor'easters that affected the island in the winter of 1998. The end result was considered acceptable based on qualitative and quantitative assessment of model results.

Parameter input to the CIAT is conducted via a user-manipulated dialog box and is minimal in order to facilitate ease of use. In addition, data and model output from the CIAT allows for the 3-dimensional (3D) visualization of data layers and the SSIS output layer. It is anticipated that the CIAT will be applicable to additional coastal regions with minor modifications and that migration to a web-enabled tool will be a possible future product evolution.

In summary, the purpose of the CIAT tool described here is:

- Improved modeling of coastal impact as a result of hurricanes and nor'easters (incorporating the SSIS methodology and improved coastal physical models into a rapid-update-cycle GIS-based tool with $3 \mathrm{D}$ visualization capability) 

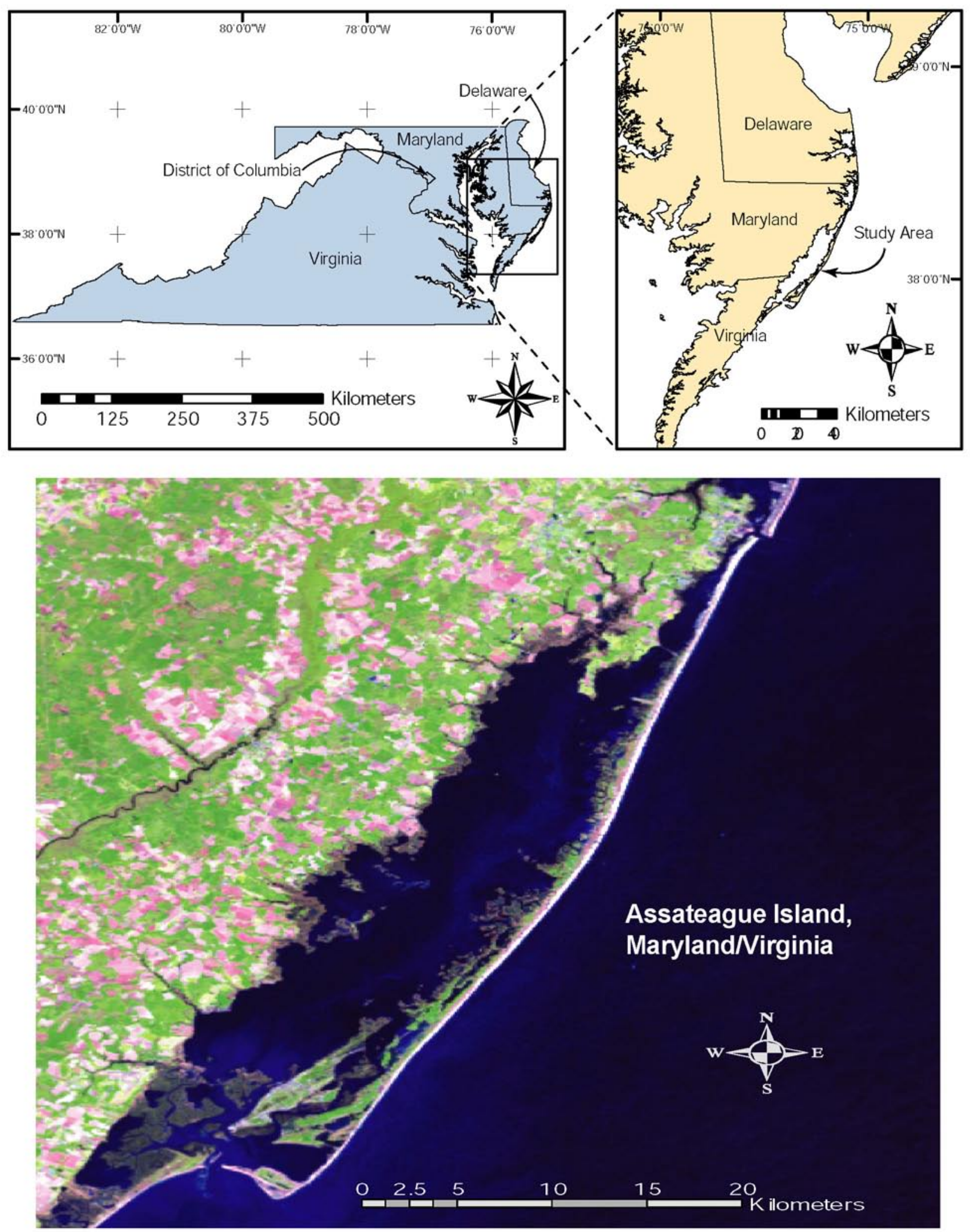

Figure 1. General location of Assateague Island, Maryland/Virginia (Top). False-color satellite imagery (Landsat) of Assateague Island (Bottom). 
- The utilization of new technology in advancing the understanding of coastal hazards (LIDAR, and especially EAARL LIDAR)

- The creation of a location-independent digital coastal impact prediction tool for use by research scientists, the general public, and coastal managers

\section{Data Preparation and Installation}

Essential requirements for successful CIAT use, each described within this section, include:

- ArcGIS 8.X series of GIS products

- ArcGIS Spatial Analyst

- A file containing values for the slope of the foreshore (beach slope file) processed for CIAT usage, in raster format

- A D-high (height of the primary dune crest) file processed for CIAT usage, in raster format

- Ancillary data for CIAT interpretation (Data layers such as air photos, DEM's, etc.)
- Installation of required directories

- Empirical parameters for CIAT calculations

It is assumed that any user of the CIAT is familiar with the ArcGIS suite of products, GIS utilization in general, and ESRI extension modules such as ArcGIS Spatial Analyst. The CIAT script files are designed to be used with ArcGIS 8.x because ArcGIS 8.x scripts are composed in Visual Basic for Applications (VBA). Initial testing with the newest version of ArcGIS (ArcGIS 9.x series) indicates that existing VBA scripts in the CIAT will need modification to be utilized beyond ArcGIS 8.x. Furthermore, because some of the scripts conduct operations on raster files, ArcGIS Spatial Analyst extension must be installed on the processing computer.

The CIAT requires both a beach slope file and a D-high file for successful operation. Ideally, these files will be derived from LIDAR-based datasets to optimize topographic accuracy. Both files should be generated to avoid any pixel gaps in a horizontal direction, such as a transect from East to West (Figure 2). Although technically the CIAT can be operated on a file with any pixel resolution meeting this initial requirement, testing of the CIAT on Assateague Island involved grids with $5 \mathrm{~m}$

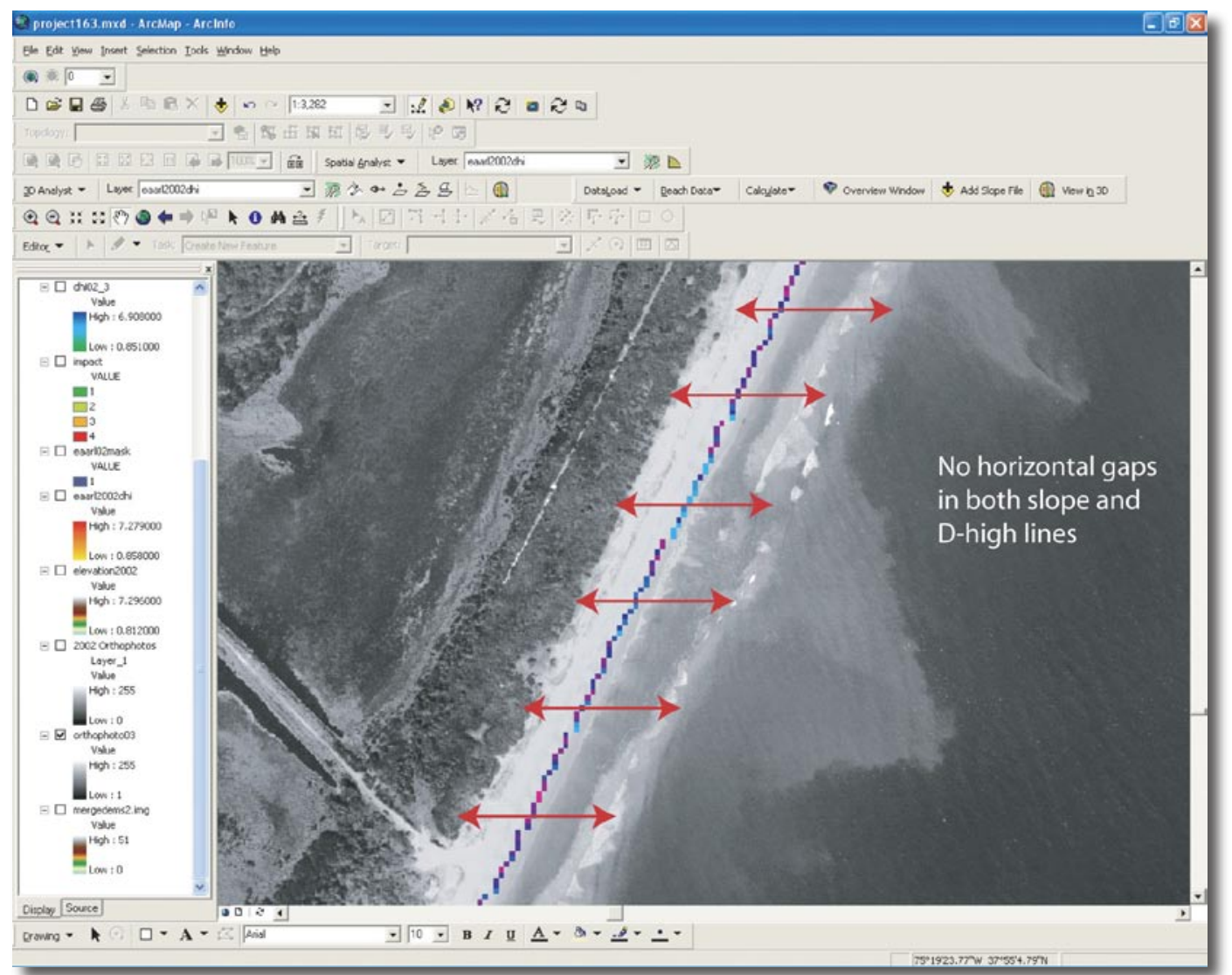

Figure 2. Example of a beach slope raster file for use in the CIAT. Note the requirement for singular pixel data along a horizontal transect in the data, with no longshore gaps. 
spatial resolution; when the CIAT was created (2004 and early 2005), tests on smaller spatial resolution grids were too computationally intensive to be conducted successfully on a personal computer.

The CIAT is supplied to a user as a zipped file (also on a CD-ROM) containing a folder named "Projects", in which a project named CIAT1.mxd is located, along with a folder named "CIATinstallationfiles" (Figure 3). Certain necessary files have been designed specifically for use with the CIAT. Installation of these files is critical for the CIAT to work properly. Specifically, the user must have a D:Itemp folder created on the hard drive. The files in the CIATinstallationfiles directory must be installed in D:Itemp; these are kernel files utilized by the "RasterModeler" within the CIAT program architecture. In addition, D: Itemp is the location utilized for storing saved raster files, model output, and analysis masks. Copy all files in this folder and paste them into the D:Itemp folder (Figure 4).

Once the CIAT project (CIAT1.mxd) is loaded in ArcGIS for the first time, it should be saved as a separate file with a different name. After the necessary files have been copied into D:Itemp, any projects containing the CIAT should work properly unless the scripting code is changed. If the files in D:Itemp should become erased or corrupted, recopy them from the original CIATinstallationfiles folder.

Ancillary data for modeling purposes includes aerial photographs, LIDAR data, and digital elevation models. These items can be hard-coded into the CIAT toolbar operation, but this is not required for a simple model run. Examples of ancillary data associated with the pilot

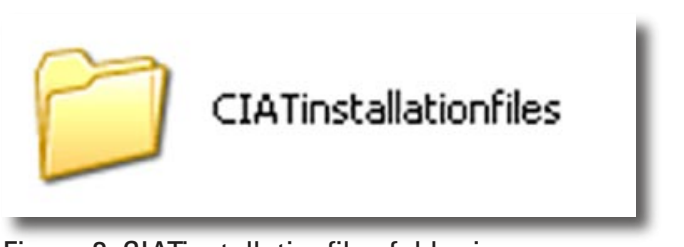

Figure 3. CIATinstallationfiles folder icon.

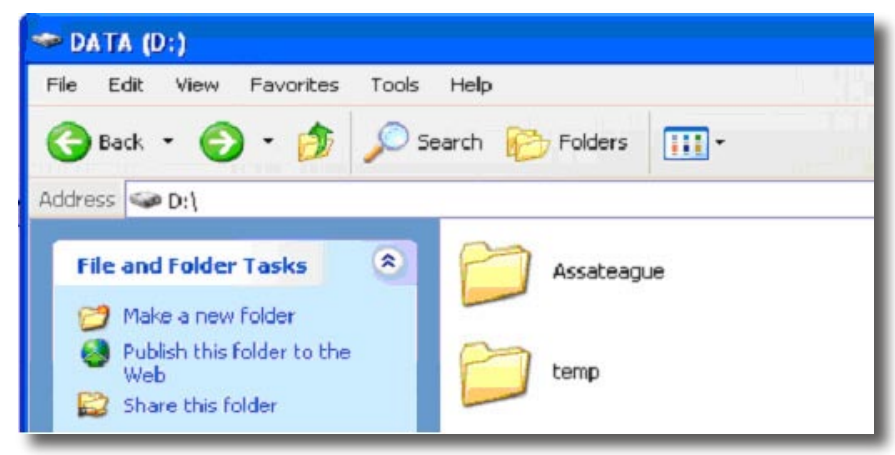

Figure 4. D:Itemp folder icon. project conducted on Assateague Island, MD/VA are illustrated in Figure 5.

\section{CIAT Project Layout}

The initial CIAT project (CIAT1.mxd) is loaded as a standard ArcGIS project file. Note that it is designed with the ArcGIS Spatial Analyst extension loaded, and ArcGIS will look for this extension to be in the "on" state when the project is opened for use. Prominently located in the Data View section of the project is the CIAT toolbar (Figure 6), which contains all the functionality of the CIAT program, including required datasets such as beach slope lines and D-high lines, ancillary dataset loading, and $3 \mathrm{D}$ viewing capability.

Datasets may be loaded via two independent methods in the CIAT project. The traditional method, and most adaptable, involves using the Add Data button on the main toolbar of ArcGIS. The Add Data button is depicted in Figure 7. The Add Data dialog box can also be accessed on the CIAT toolbar under the Add Slope File menu item (Figure 8).

The CIAT toolbar also allows for the hard-coding of datasets, where speed of model runs is paramount to unlimited numbers of ancillary datasets. Hard-coding can be accomplished by utilizing the ArcGIS customization function to access the VBA code for each data type. The pathname, layer name, and layer type can then be altered. These changes are best performed by someone familiar with VBA and ArcScripts, but they can be accomplished by an intermediate-skilled GIS user. In addition, the Customize function within ArcGIS allows one to change the name and/or button image within the CIAT toolbar and embedded commands. Ancillary data for the pilot project on Assateague Island have been hard-coded into the original CIAT project. These files will not work when the project, CIAT1.mxd, is loaded unless the folder titled "Assateague" and all its contents are placed in the D:I drive (if the user is installing this folder, ensure that it is at the top directory level, as in D:\Assateague). These datasets can be accessed under the DataLoad and Beach Data menus (Figure 9).

The DataLoad menu, which will only work correctly with hard-coded files, offers quick access to data such as aerial photographs, LIDAR data, Digital Elevation Models (DEMs), and data pertaining to the historical storm of record in a particular location, once coded in. The menu, which follows a similar format throughout all items in the CIAT toolbar, is designed in cascade style (Figure 10), and all the menu items containing the cascade-style orga- 

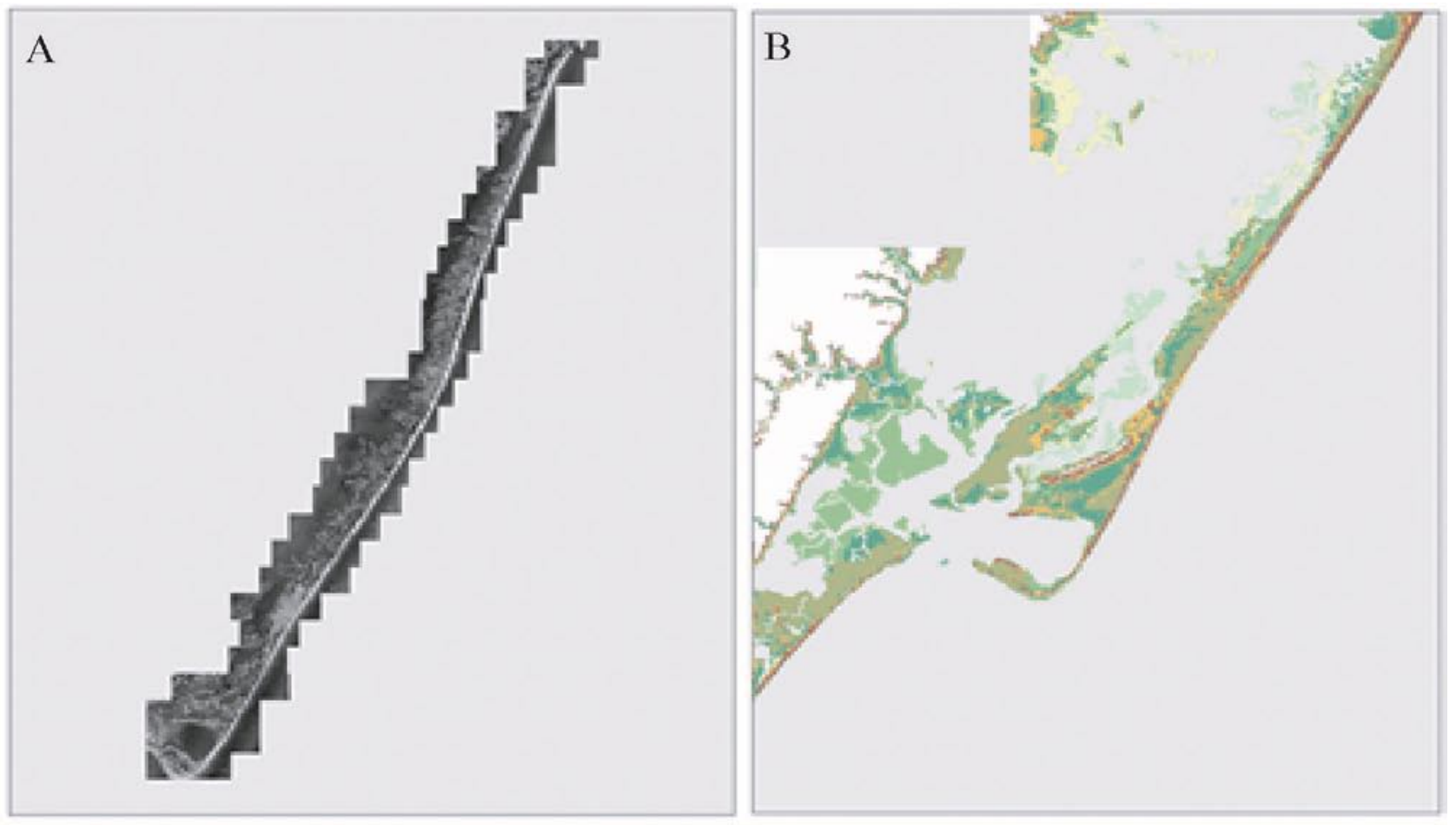

C

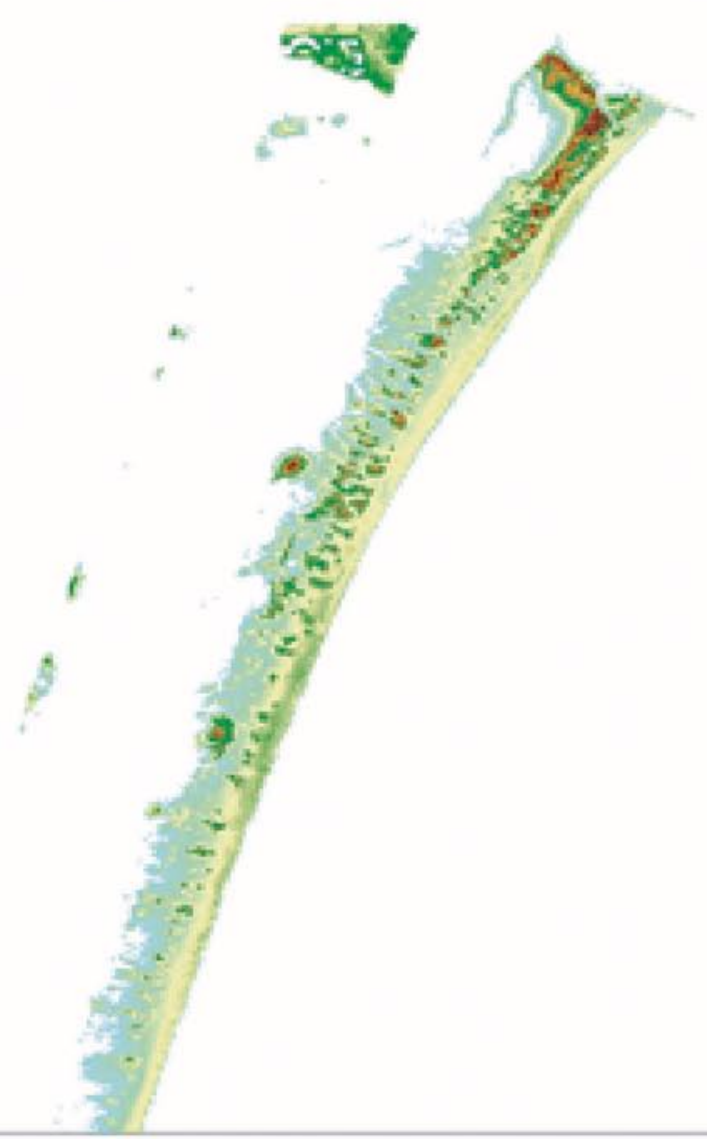

Figure 5. Examples of ancillary data that can be included in a CIAT project. A) Aerial photographs, B) Digital Elevation Models (DEMs), and C) EAARL LIDAR data. In these examples, all data pertain to Assateague Island, Maryland/Virginia. 


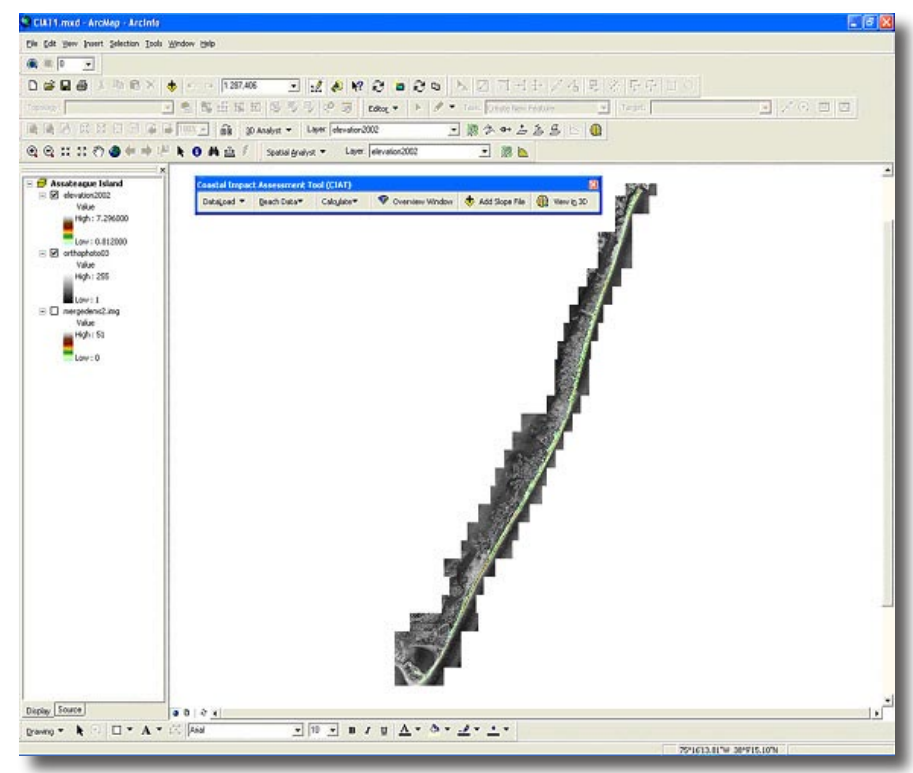

Figure 6. The Coastal Impact Assessment Tool toolbar and sample datasets.

\section{$\pm$}

Figure 7. The Add Data button.

\section{dow $\$ add Slope File}

Figure 8. The Add Slope File button on the CIAT toolbar. This button can be used to add any file to the table of contents, despite its name.

\section{Coastal Impact Assessment Tool (C) \\ Dataload - Beach Datar Calc}

Figure 9. The DataLoad and Beach Data menu items in the CIAT toolbar.

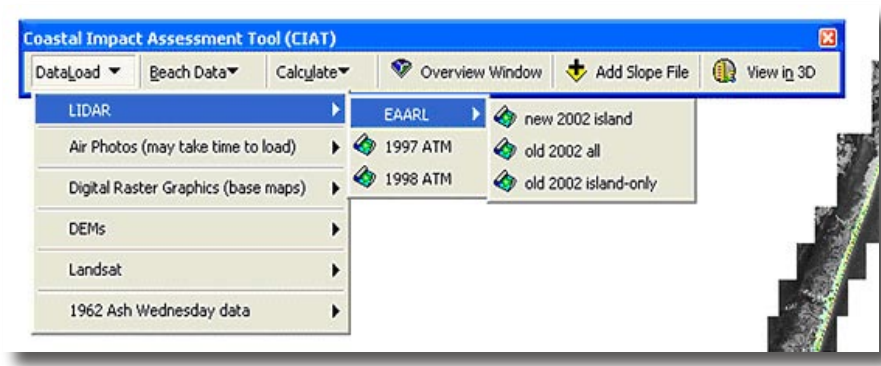

Figure 10. Cascade-style design of the menu items in the CIAT toolbar. nization are noted by a downward pointing arrow on the right side of the menu title. The Calculate menu contains the major functions of the CIAT modeling process and is covered in detail in the next section.

Two other components of the CIAT toolbar are the Overview Window and the View in 3D commands. The View in 3D menu command opens up ArcScene, which is a $3 \mathrm{D}$ viewer for GIS-based data, and the use of this menu is described at the end of this document. The Overview Window is used to quickly pan through the dataset currently in the Data View, and also to get a quick view of the data extent. Figure 11 shows the Overview Window, which is titled by the name of the Data Frame. The area bounded in blue in the Overview Window depicts the zoomed-in image in the Data Frame, and the entire data extent is shown in the rest of the window.

\section{CIAT Modeling Functions}

The primary purpose of the CIAT and its modeling toolbar is to calculate the predicted impact of coastal storms. Some preparation is necessary by the user in order to conduct effective model runs. Several items of empirical data must be gathered prior to beginning calculations. These items include:

- Nearshore wave heights

- Wave periods

- Tide and storm surge values

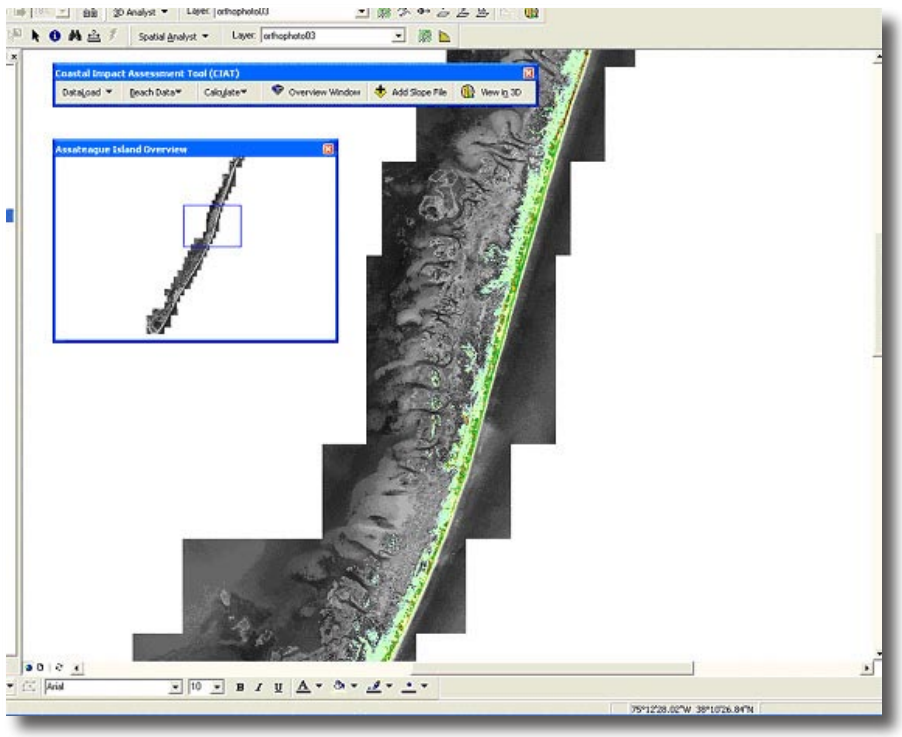

Figure 11. Example of the Overview Window. 
- Beach slope and D-high line files are required, but these are generally created in a remote-sensing application such as Imagine and then imported into ArcGIS using the Add Data or CIAT toolbar

Assuming that these items have been gathered by a user, this section describes in detail the usage of the CIAT modeling functions and utilizes a sample run for illustration purposes.

The CIAT toolbar contains a menu titled "Calculate" (Figure 12).

The CIAT contains a Single-Instance Runup Calculator for the calculation of R-high and R-low values based on user-input parameters as listed on the preceding page. The formulas used throughout the CIAT calculations are displayed in Figure 13.

The Single-Instance Runup Calculator function is valuable where data are provided in list form and one wants a numerical, rather than cartographic, output. This information can be processed in other software options, such as Matlab, but the design of this tool and its simplified structure add value to the CIAT product. When the Single-Instance Runup Calculator is selected in the

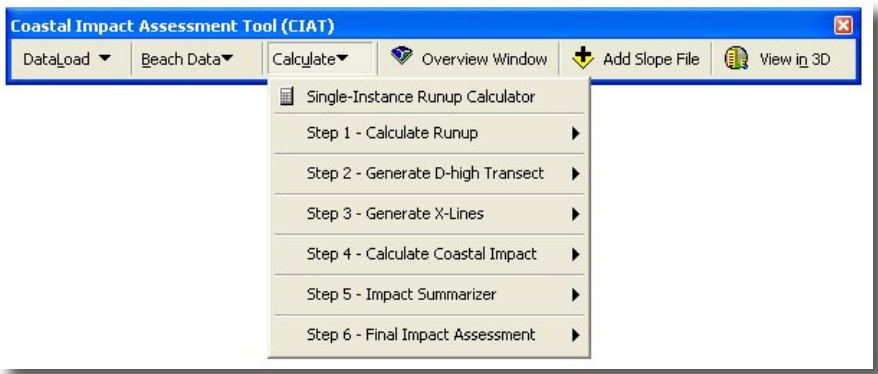

Figure 12. Calculate menu and subcommand menu. The Calculate menu is the heart of the CIAT.

$$
\begin{gathered}
R_{\text {high }}=R_{2 \%}+\text { tide } \\
R_{\text {low }}=R_{\text {high }}-S_{2 \%} \\
R_{2 \%}=0.35 \beta_{f}\left(H_{0} L_{0}\right)^{1 / 2}+\frac{\left[H_{0} L_{0}\left(0.563 \beta_{f}^{2}+0.004\right]^{1 / 2}\right.}{2} \\
S_{2 \%}=H_{0}\left(0.85^{*} \frac{\beta_{f}}{\sqrt{H_{0} L_{0}}}+0.06\right) \\
\xi_{0}=\beta /\left(H_{0} / L_{0}\right)^{1 / 2}{ }_{\text {Holman (1986); Stockdon et al.(in review) }}
\end{gathered}
$$

Figure 13. Equations used to model R-high and R-low values in the CIAT.
Calculate menu, a dialog box will open, as illustrated in Figure 14.

Here, the use of all CIAT modeling features is illustrated by way of an example. For all steps outlined, wave height will be assumed as $1.5 \mathrm{~m}$, wave period as $8 \mathrm{sec}$., and tide/surge as $1.5 \mathrm{~m}$ (and for the calculator only, assume a beach slope of 0.05). Figure 15 depicts the results of entering these parameters into the SingleInstance Runup Calculator and then clicking the Calculate R-High button.

Clicking the R-Low button will calculate the corresponding parameter (not shown). The tool is designed to

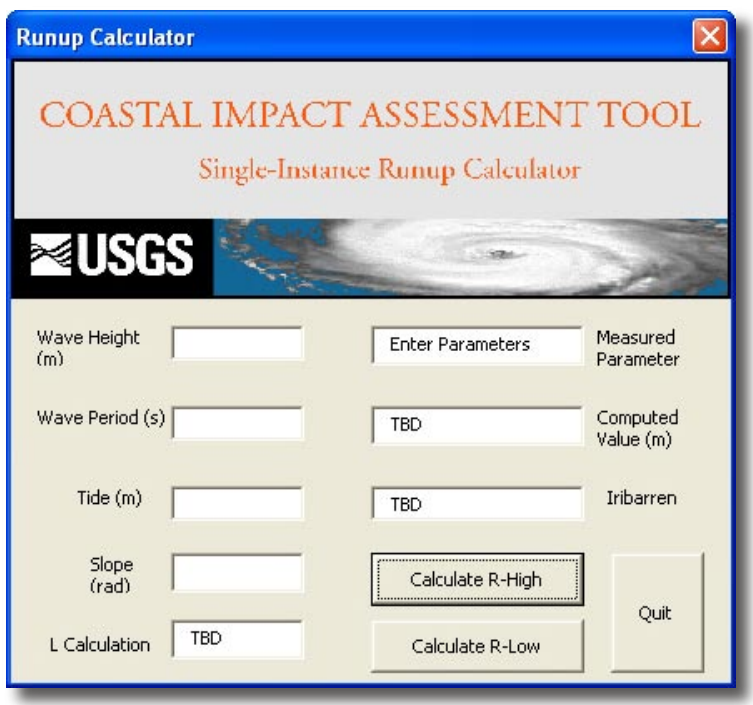

Figure 14. Dialog box for the Single-Instance Runup Calculator. The user must enter the parameters required by the empty text boxes.

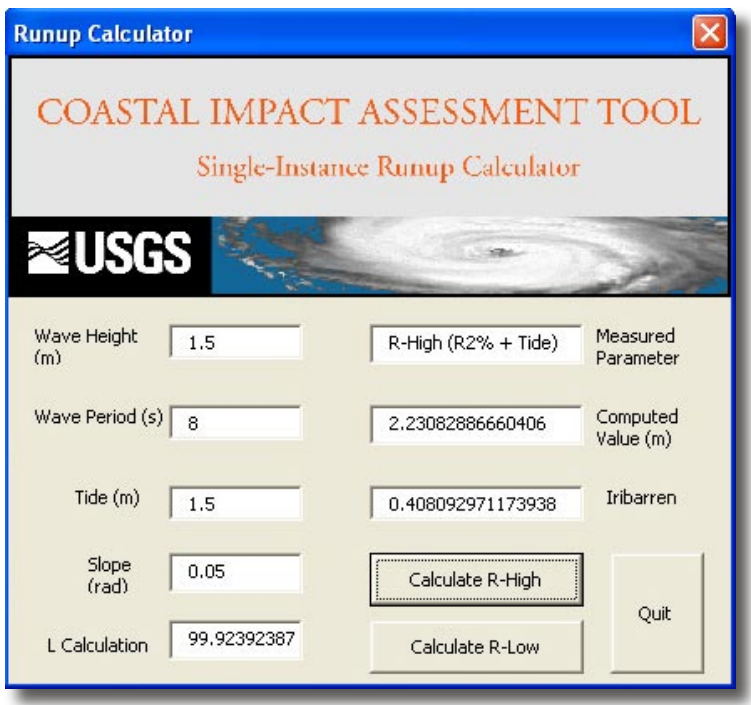

Figure 15. Example R-high calculation assuming a wave height of $1.5 \mathrm{~m}$, wave period of $8 \mathrm{sec}$, tide/surge value of $1.5 \mathrm{~m}$, and a beach slope of 0.05 . 
determine reflective versus dissipative beaches appropriately, and alter the calculated value accordingly.

The Single-Instance Runup Calculator is designed for a single location along the coastline; therefore, it is not suitable for modeling large sections of coastline. For these purposes, users will utilize Step One through Step Six of the Calculate menu.

To model coastal impact, beach slope and D-high lines must be available and in a format recognized by the CIAT model. The CIAT is flexible in allowing for different methodologies to be utilized in calculating the D-high values/locations and the beach slope values/locations. The only absolute requirement is a pixel value for every horizontal transect, as illustrated in Figure 3. This means that there will be at least one pixel with a value for every unit of the spatial resolution used for the project. In addition, the spatial resolution of the D-high raster and the beach slope raster must be the same. For example, a spatial resolution of $2 \mathrm{~m}$ in the beach slope raster should be echoed by a spatial resolution of $2 \mathrm{~m}$ in the D-high file. It is best if both files are derived from the same LIDAR dataset by using remote-sensing software for data extraction. For the pilot project example here, the spatial resolution utilized is $5 \mathrm{~m}$. Both D-high and beach slope files were generated from EAARL LIDAR data. The D-high files were generated by using spatial profiles every $50 \mathrm{~m}$ along the coast to determine the dune crest (Figure 16). The beach slope files were created by determining an elevation for the mean high water (MHW) based on NAVD88 estimates between Chesapeake Bay and North Carolina (given as $0.81 \mathrm{~m}$ at Assateague, in consultation with H. Stockdon, USGS), and then computing slope between the pixel at or exceeding MHW and the adjacent landward pixel. This slope calculation procedure is not a requirement for successful operation of the CIAT model. As long as the requirements for no missing data (gaps) on a horizontal transect are adhered to, alternate methods of both beach slope and D-high computation are acceptable and should not violate the CIAT's programming code. However, both the slope lines and D-high lines should have the same spatial resolution.

\section{ZIC Mask Generation}

A mask of the island area to be analyzed for coastal impact must be created. In order to accomplish this step, a user must create the mask using commands in the Raster Calculator.

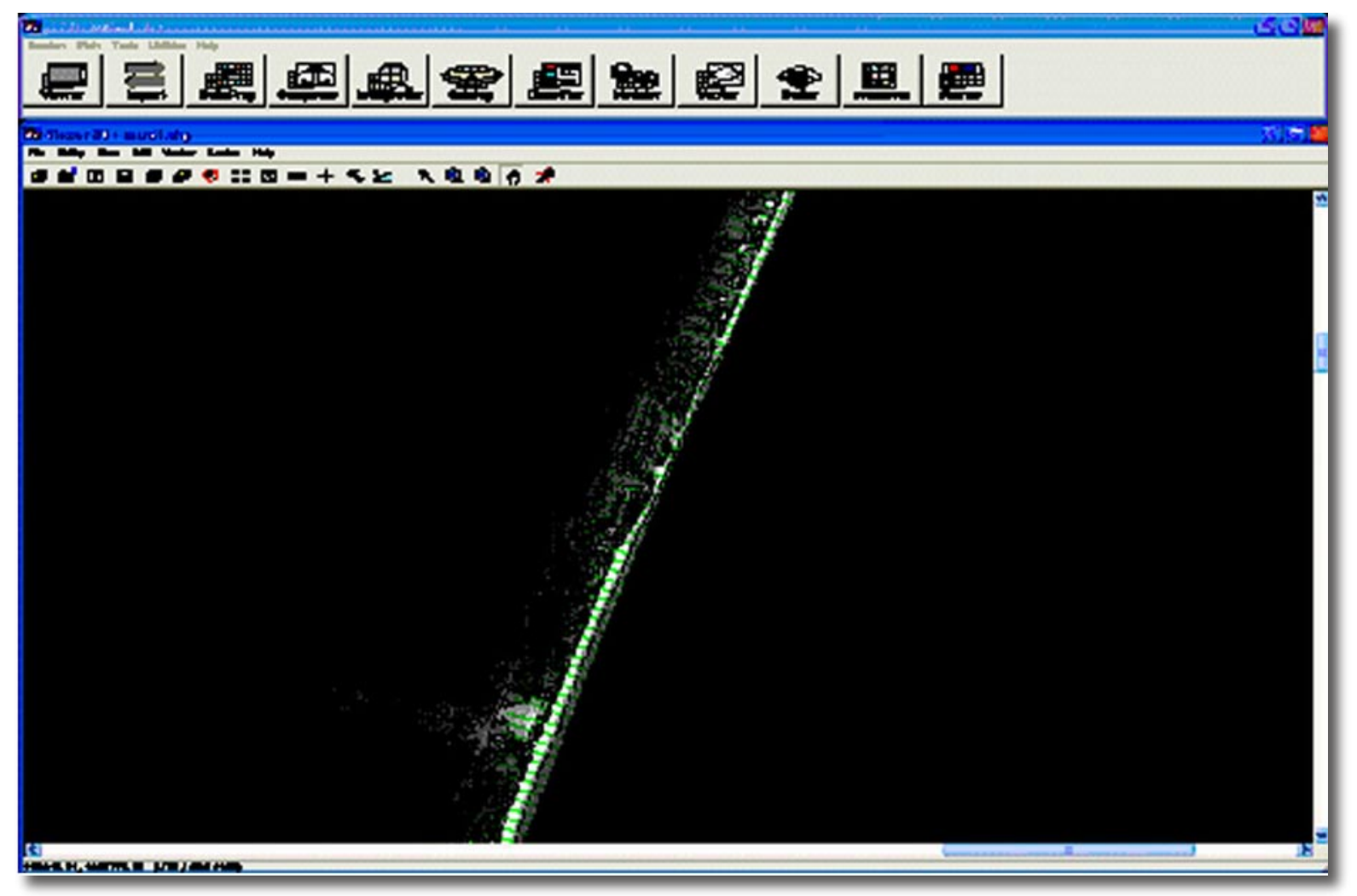

Figure 16. Transects were generated every $50 \mathrm{~m}$ along the coastline in order to determine locations for spatial profiling to derive D-high values. Transects were generated in the Digital Shoreline Analysis System (DSAS), a GIS -based shoreline change tool, and then overlaid on top of LIDAR shore topography data. 
This step is not automated for adaptability reasons. If the CIAT is used in different regions of the U.S. coastline, the distance between the D-high line and the beach slope line (the Zone of Impact Calculation - ZIC) may vary. Therefore, it is important to adjust any parameters relating to this zone before running the model. By utilizing command-line functions to execute this mask creation task, a user can change the kernel files to reflect the ZIC more accurately. Since these kernel files are used in later steps, the modeling process is then effectively calibrated for the Region of Interest (ROI) that is being modeled.

To generate the island mask, click the Spatial Analyst tab and then scroll down to click on the Options button at the bottom of the menu. At the top of the Options dialog box is an input box for the working directory. Ensure that the destination in the working directory is D:Itemp, where the CIAT installation files were copied earlier, as illustrated in Figure 17. Once the working directory is set, scroll down the Spatial Analyst menu and select the Raster Calculator button (Figure 18), which will open the actual Raster Calculator (Figure 19).

The Raster Calculator is an extremely powerful tool for working with raster-based datasets in ArcGIS. One of the commands that the Raster Calculator will perform is called Focalmax (for a detailed description of Raster Calculator commands, see the help menu of the ArcGIS Spatial Analyst extension). Focalmax essentially creates transects of values from the files used here, such as the D-high and slope files.

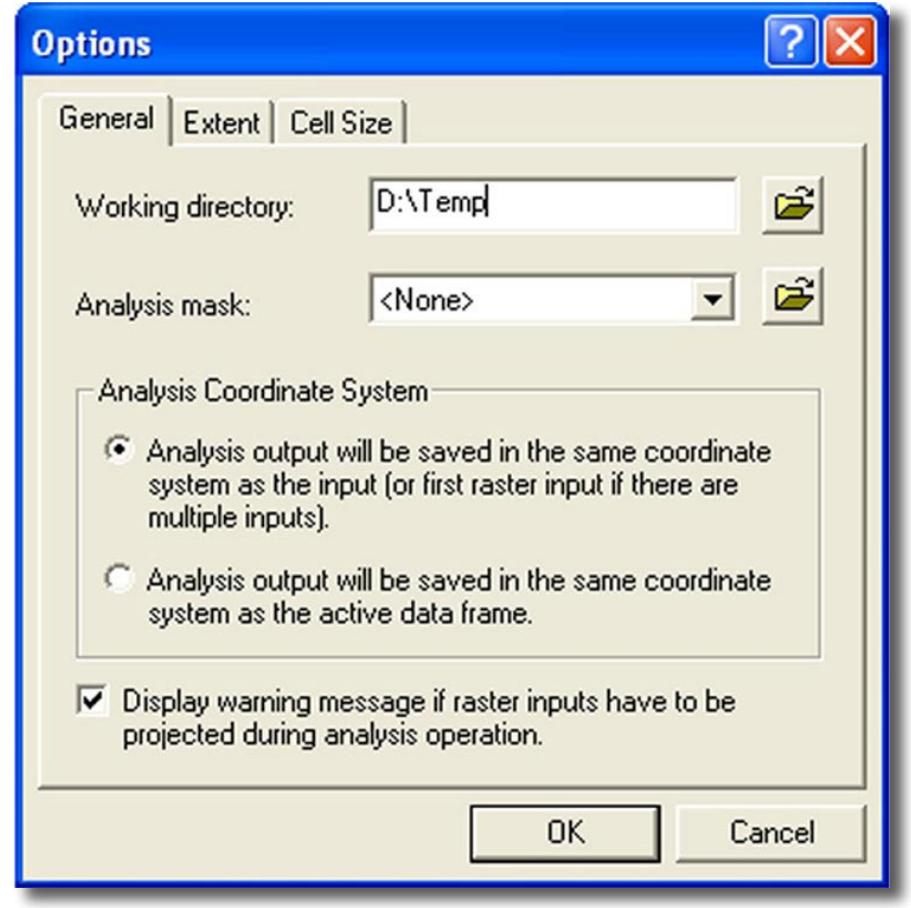

Figure 17. The working directory for the ArcView Spatial Analyst extension should be set to D:Itemp in the Options dialog box.
To begin the ZIC mask creation process, type the following syntax into the Raster Calculator:

\section{xNAMEx $=$ focalmax $([\mathrm{zNAMEz}]$, irregular, left.txt, data)}

where $x$ NAMEx is the name of the file to be created and zNAMEz is the name of the already loaded beach slope file (which can be easily entered by simply double-clicking the file name in the "Layers:" box in the upper left corner of the Raster Calculator).

Click the Evaluate button. This generates a series of transects from the location of the beach slope line to the west with a length determined by the kernel file in the command (left.txt).

Next, type the following syntax into the Raster Calculator:

\section{yNAMEy = focalmax $([q N A M E q]$, irregular, right.txt, data)}

where yNAMEy is the name of the file created and qNAMEq is the name of the already loaded D-high file. This generates a series of transects that extend from the location of the D-high line to the east with a transect length determined by the kernel file (right.txt). Note that in actual use, the D-high file (orange/red) and the beach slope file (blue/purple) will be obscured by the newly created layers and will not appear on screen as they do in the images with transects shown in Figures 20, 21 and 22.

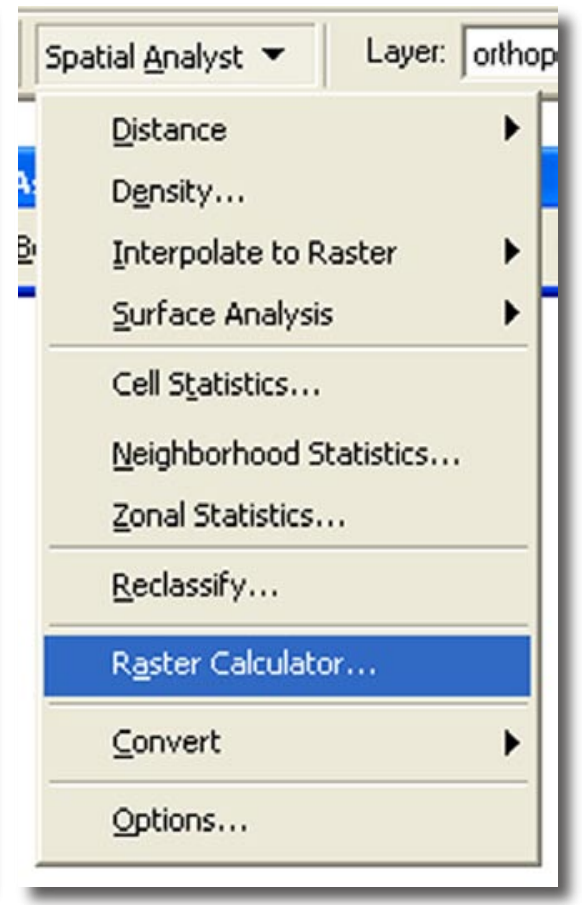

Figure 18. Raster Calculator menu selection in the Spatial Analyst extension menu. 


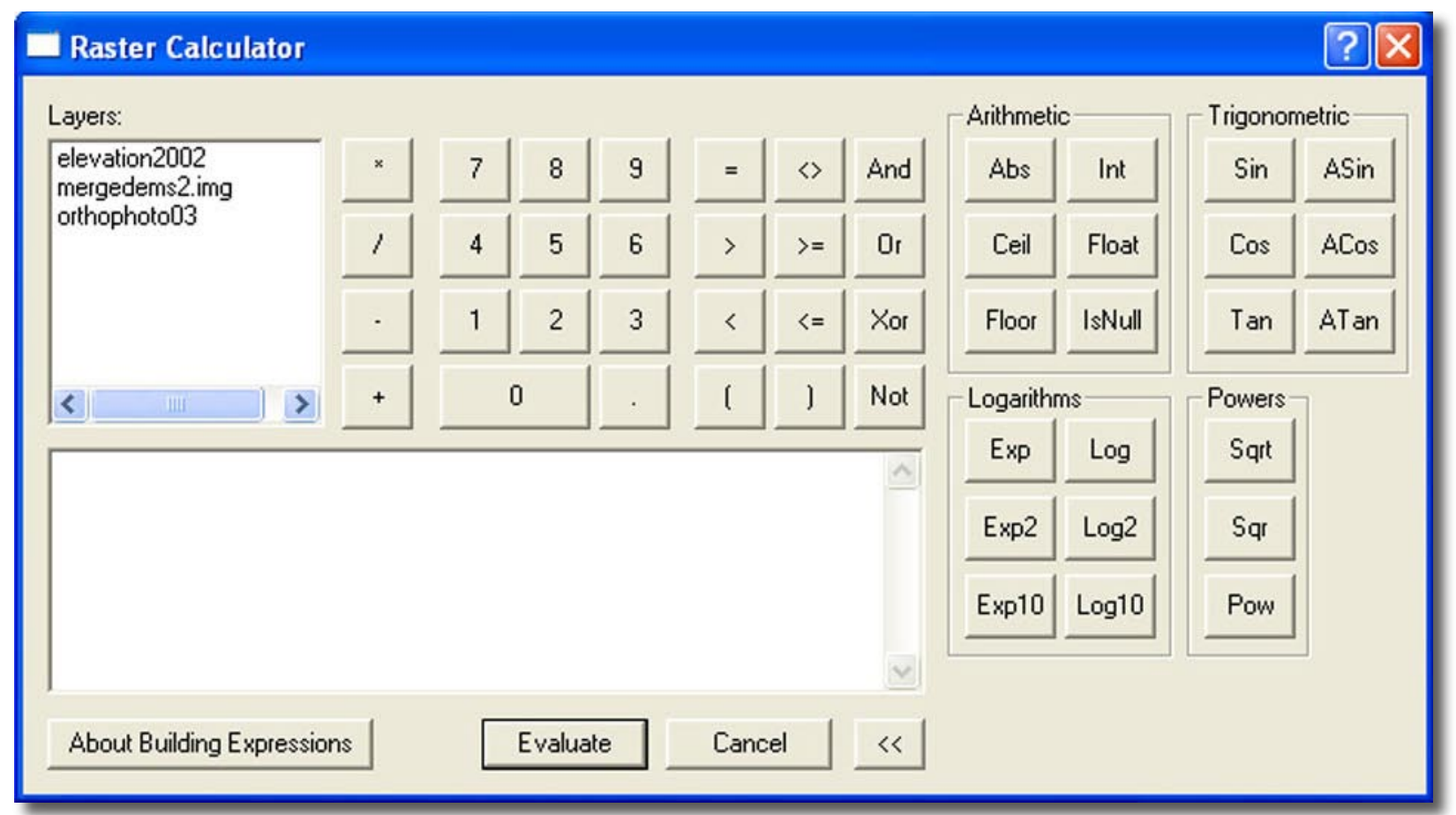

Figure 19. The Raster Calculator command box.

Now that both mask transect files have been created, there is one final step to create the mask. This step filters the transects to include only the areas in which actual values exist (areas outside the transects are treated as null values, otherwise called No Data). Therefore, open the Raster Calculator, and with both transect files loaded in the table of contents, utilize the following command:

\section{SNAMEs $=\operatorname{con}([y N A M E y]>-80 \&$ $[\mathrm{xNAMEx}]>\mathbf{- 8 0 , 1 , 0 )}$}

where sNAMEs is the new file name for this last step and yNAMEy and XNAMEx are the filenames from the previous two steps. The result of this command will yield

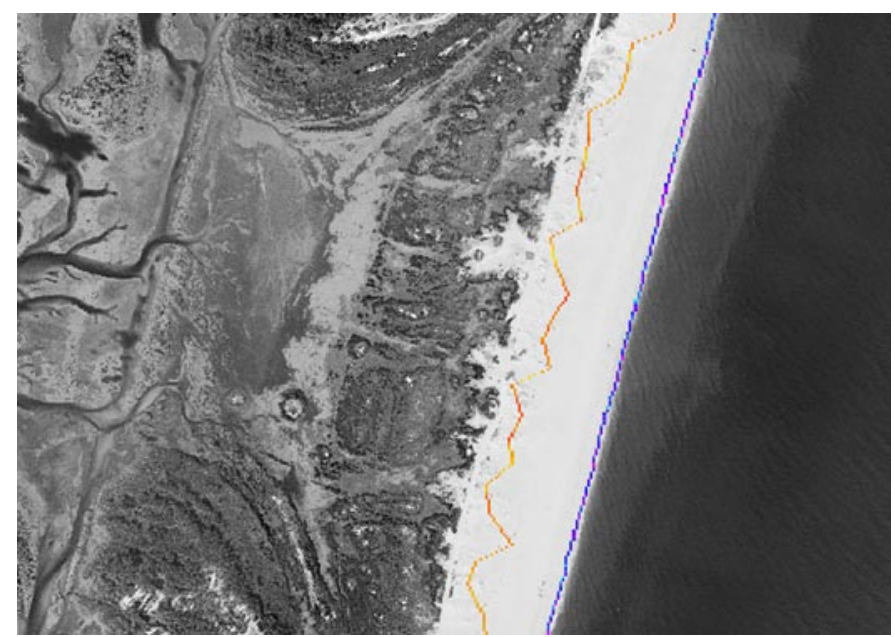

Figure 20. Beach slope and D-high (orange) lines created from raster files (here, $5 \mathrm{~m}$ spatial resolution). a file that looks something similar to Figure 23, when the transect layer displays have been turned off.

This file is the ZIC mask file, which represents the spatial extent of the CIAT model output. The other transect files can be deleted or removed from the table of contents if desired. Leave the ZIC mask file in the table of contents because it will be needed for later CIAT modeling steps. Unless locations, D-high files, or beach slope files are changed, the ZIC mask file will be utilized without any further changes or command-process steps. It is therefore necessary to save the ZIC mask file

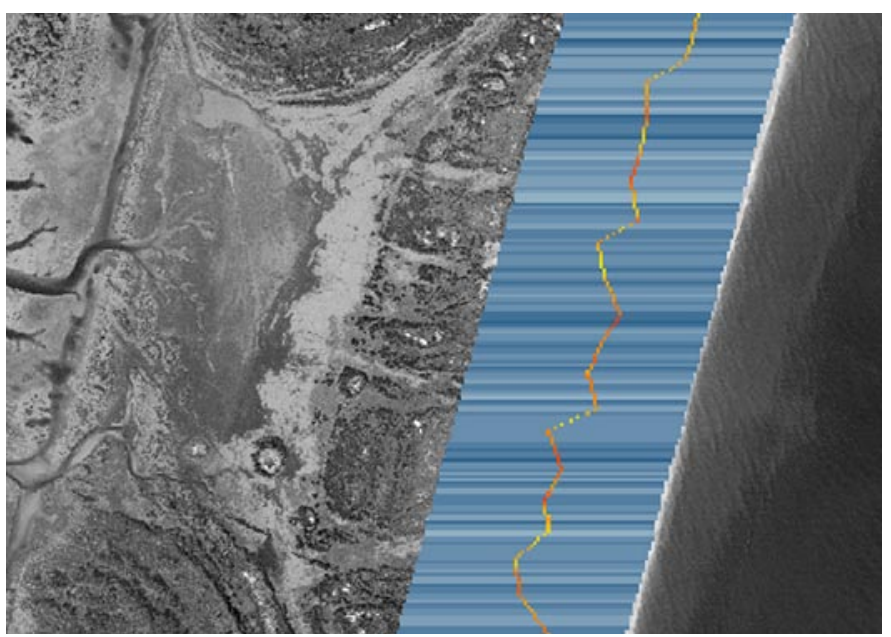

Figure 21. Transects following the completion of the transectgeneration command with the D-high line. 


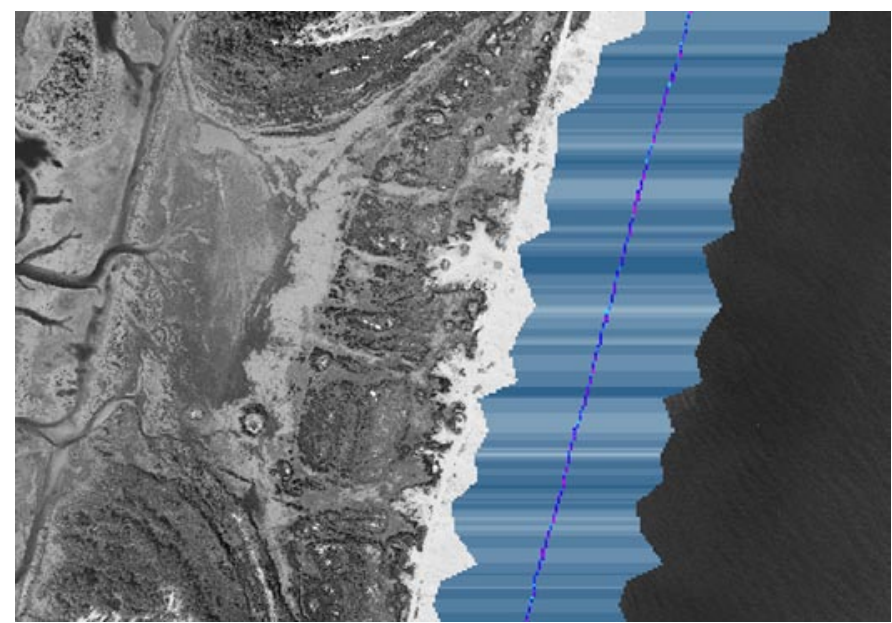

Figure 22. Transects generated after completion of the command utilizing the beach slope file.

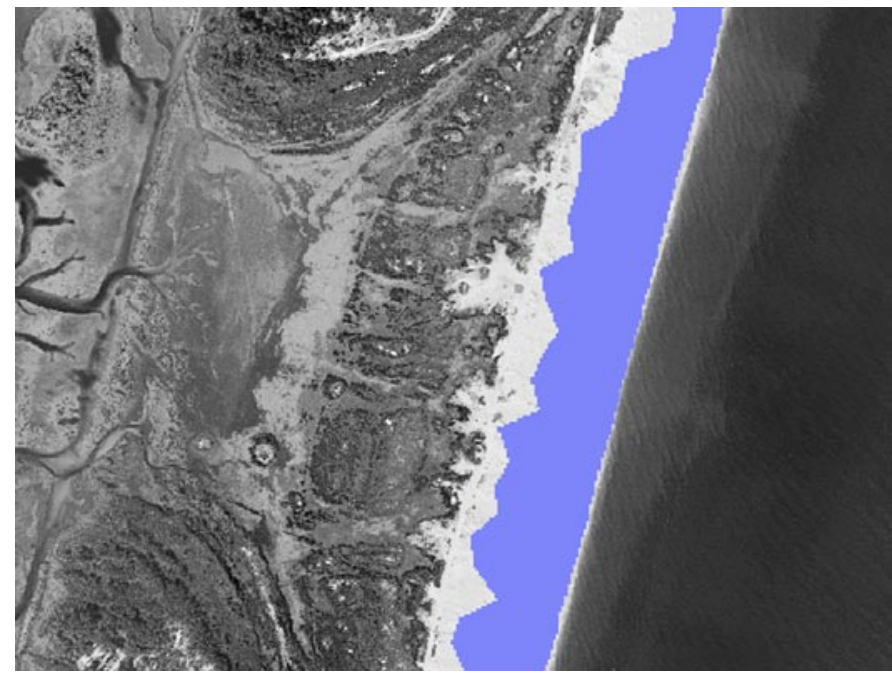

Figure 23. The end result of the ZIC mask generation process shows the portion of the island for which the CIAT will estimate the impact from coastal storms.

in a separate location from D:Itemp, the current working directory.

If there are problems with the ZIC mask creation process that involve the transects being too short for the distance between the D-high line and the slope file line, this can be corrected in the text editor. Make sure that the original text file is saved with a different name before beginning this process in case of any mistakes while changing the kernel file. Use the editor to open the left. txt and/or right.txt file and adjust the size by adding 0's and 1's to the file. Always add an odd number of both, and exactly the same quantity. For example, if the files must be extended by three pixels in each direction, open the left.txt file and add three 0's and three 1's, then do the same to the right.txt file. It is always better to overestimate the extension than to underestimate.

\section{A Sample Model Run Using the CIAT}

\section{CIAT Runup Calculator -- Step One}

Now that the ZIC mask is prepared, the user is able to run the CIAT model. The CIAT is a rapid-updatecycle model and is capable of generating a final product in less than an hour; most tests have indicated timeto-results at approximately 45 minutes. On the CIAT toolbar, use the Calculate menu to select Step One - Calculate Runup. Figure 24 shows the calculation of R-high using the example parameters specified earlier.

Click the Calculate Runup button to begin the calculation process. When the new raster is added to the table of contents (this may take some time), click the Quit button. When the calculation of R-high is complete, this procedure should also be run on the R-low calculator, also located under Step One on the Calculate menu (Figure 25). Click the Quit button on the R-low calculator to close the dialog box. Two files will be created at the top of the table of contents on the left portion of the ArcGIS screen (Figure 26).

Right click on the title of the first created raster (Figure 27). A new menu will appear on screen, and the option to Make Permanent (second from bottom) will appear. This option can be used if the model results are satisfactory and the raster file is to be saved as a permanent file, with a different name or in a new location. In any case, the name of the file should be changed.

After determining whether or not to save the file as permanent, again right-click on the first raster created and scroll down to click on Properties. Select the General

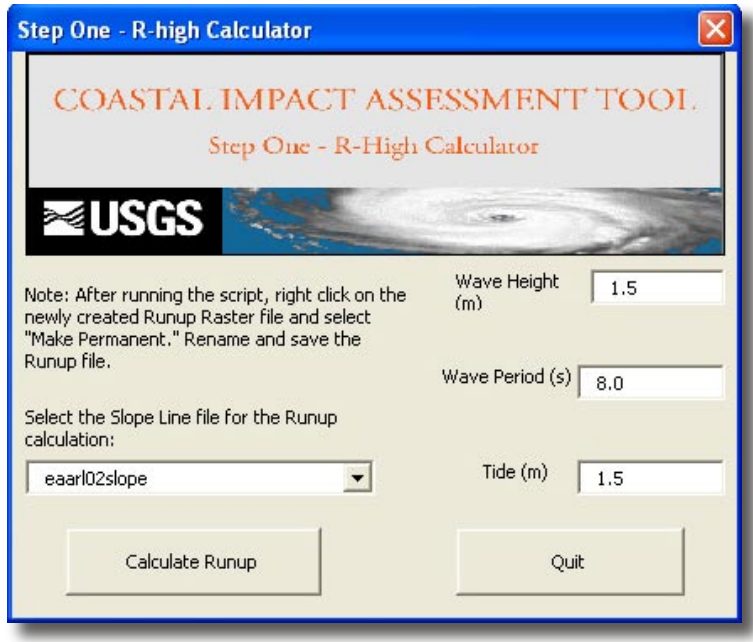

Figure 24. CIAT Step One - the wave runup calculator, in this case, $\mathrm{R}$-high. Sample parameters, as specified earlier in the text, are utilized for this example. 


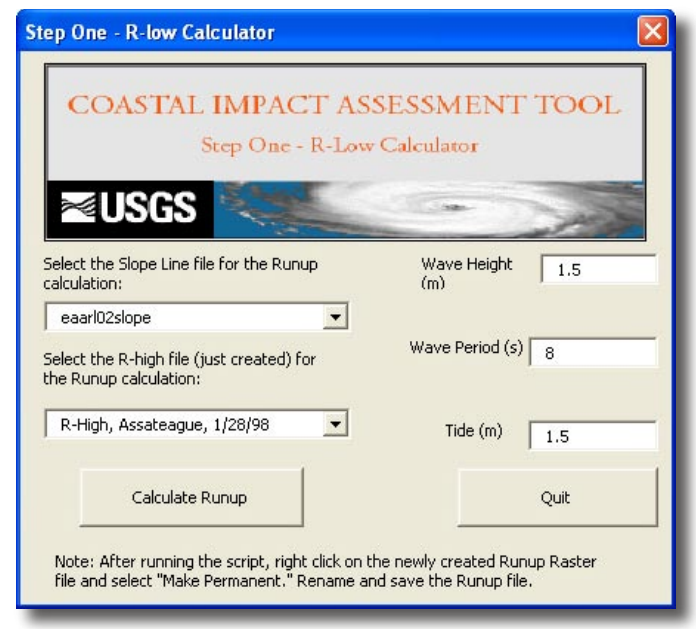

Figure 25. CIAT Step One - R-low calculator.

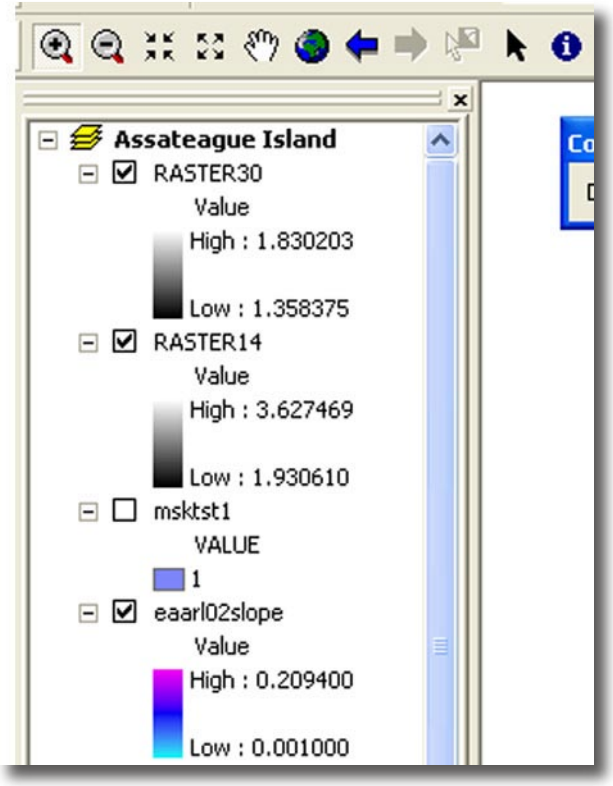

Figure 26. Two raster files are created after completing Step One. The files in the table of contents on the left are arranged in order from the newest added (top) to the oldest (bottom). The raster file on top is the R-low file, and the raster file just below it is the R-high file.

tab, and enter an appropriate name for the R-high file (and again for the R-low file), as depicted in Figure 28. The user should ensure that the names chosen indicate which file is R-high output and which file is R-low output. Upon completion of this step, the user is ready to continue with the modeling process.

\section{Generate D-high transects - Step Two}

Select Step Two - Generate D-high Transects under the Calculate menu (Figure 29). This tool generates transects of D-high values that will be utilized in the next step to compute X-lines.

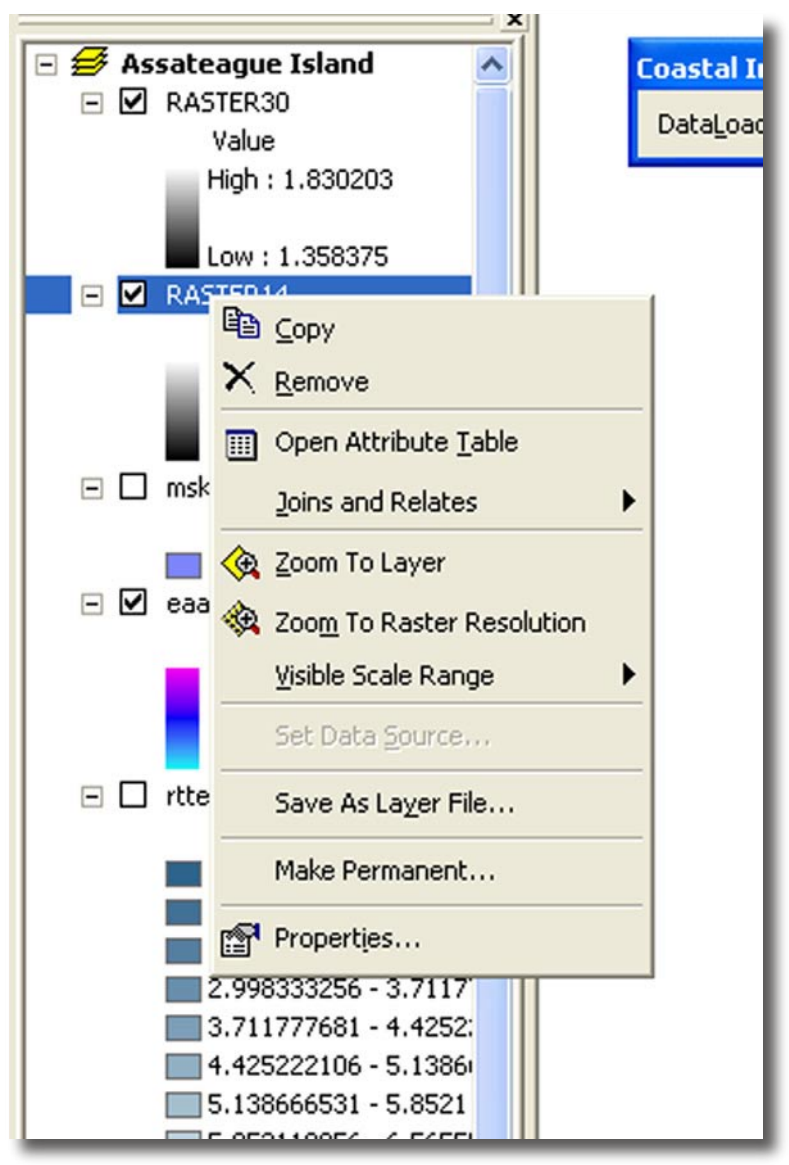

Figure 27. Right-click on any file in the table of contents and a submenu will open.

Select the D-high line file used in the model (and loaded into the table of contents on the left side of the screen), and click the Generate D-high Transects button (Figure 30). The transects will be generated and then displayed onscreen. Click the Quit button when complete and rename the file as described in Step One.

\section{Generate X-lines - Step Three}

The X-line generator, Step Three, generates the values that are utilized to determine the Sallenger StormImpact Scale for given storm parameters. The StormImpact Scale Diagram from Sallenger (2000) utilizes two variables (Figure 31). The Y-axis, which represents the ratio of R-high to D-high, is hereby referred to as $\mathrm{X} 1$. The $\mathrm{X}$-axis, which represents the ratio of $\mathrm{R}$-low to $\mathrm{D}$ high, is hereby referred to as X2. X1 and X2 raster files are generated by the CIAT in Step Three.

Manual selection of the appropriate files containing R-high (Step 1), R-low (Step 1), and D-high (Step Two) transects is accomplished within the tool (Figure 32). In Step Three, select the appropriate files and click the Generate X1 file button. Upon completion, reselect appropri- 


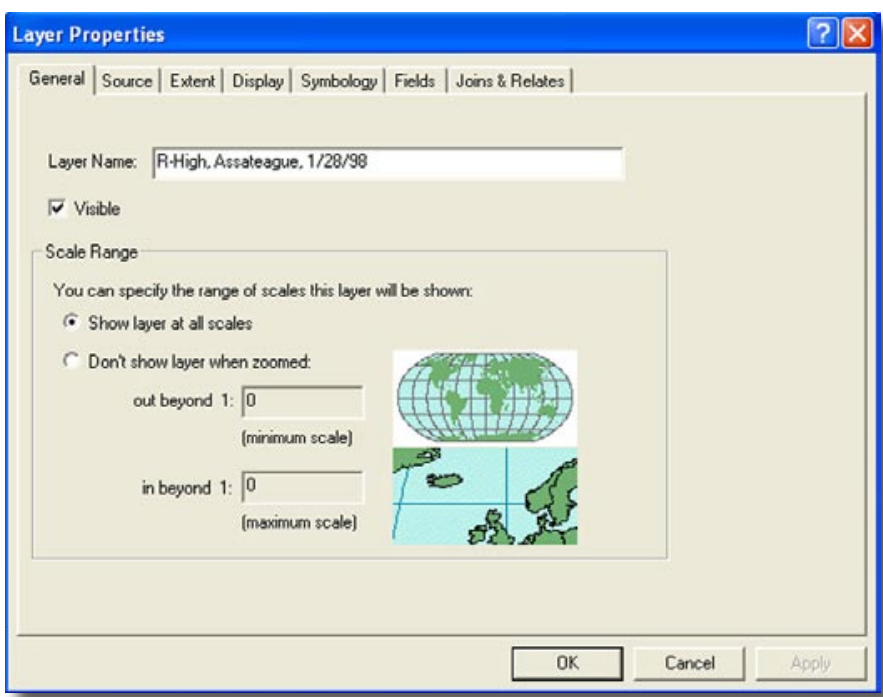

Figure 28. Layer Properties dialog box used to rename files.

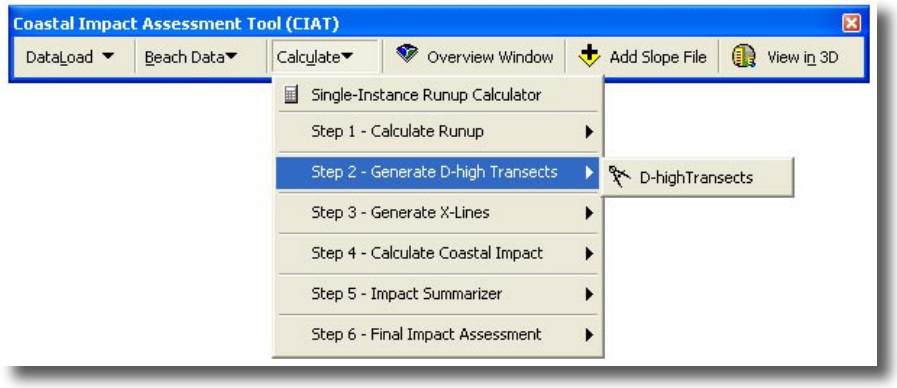

Figure 29. The Generate D-high Transects command.

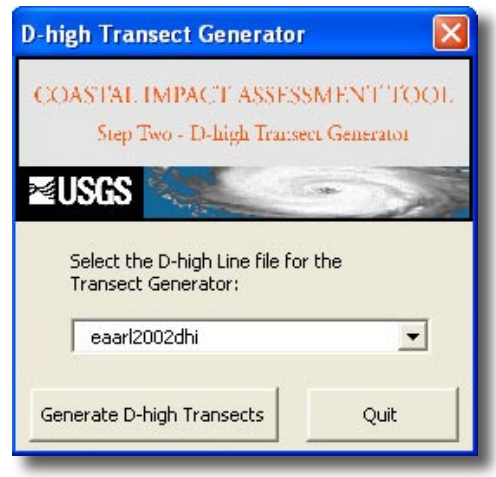

Figure 30. The CIAT Step Two dialog box.

ate files and click the Generate X2 file button. After both files have been completed, click the Quit button. Rename the files created, using the Properties sub-menu of each file, to reflect X1 or X2 status. Again, R-high/D-high is $\mathrm{X} 1$ and $\mathrm{R}-$ low/D-high is $\mathrm{X} 2$.

\section{The Coastal Impact Calculator - Step Four}

The Coastal Impact Calculator (CIC) is used to calculate the four impact classes possible from coastal storms. The operation of the CIC is a little more user intensive than the previous steps in that it requires reselecting the files in the comboboxes (list of files in the table of contents) after each calculation. This is to prevent the wrong files from being selected as each coastal impact class is generated by a click-event.

Select the X1 and X2 files, by name, in the comboboxes and then click the generate button for Coastal Impact 1 . The user MUST then RESELECT the files needed for Coastal Impacts 2-4 (Figure 33). Four new rasters should be created by this process. Upon completion, the user should click the Quit button, which will close the dialog box. Rename the rasters, starting with the first created raster, as Impact 1-4, as appropriate.

The files created by the CIC as Impact 1-4 represent the Swash (coastal impact 1), Collision (coastal impact 2), Overwash (coastal impact 3), and Inundation (coastal impact 4) regimes on the Sallenger Storm-Impact Scale.

\section{The Impact Summarizer - Step Five}

Step Five of the CIAT summarizes the four impact lines created into the previous step. This effectively creates the storm impact categories along a coastline based on the user-input parameters in the beginning steps.

Click on the Summation Tool (Figure 34). Select the four impact category files created in Step 4, and then click the Summarize button (Figure 35).

Click Quit when the step is complete. There should be four values present in the resulting file, with no zero values. If the results appear stretched from 127 to -128 (Figure 36), right click, select Properties, and click the Symbology tab. Select the Unique Values option in the upper left corner and then click the OK button (Figure 37). Make sure to rename the summarized file to indicate coastal impact.

\section{The Final Impact Tool - Step Six}

The Final Impact Tool allows for the creation of the final model impact assessment. If the ZIC mask created at the beginning of the procedure is not currently in the table of contents, it must be loaded before completing this step. Intermediate files created in earlier steps leading up to the final impact raster, such as the $\mathrm{X} 1, \mathrm{X} 2$, and Coastal Impact 1-4 files, can be removed if desired by selecting each file while holding down the Ctrl button, right clicking when all desired files have been selected, and then utilizing the remove option.

Using the comboboxes in the dialog box, select the appropriate ZIC mask file and the impact file created in 


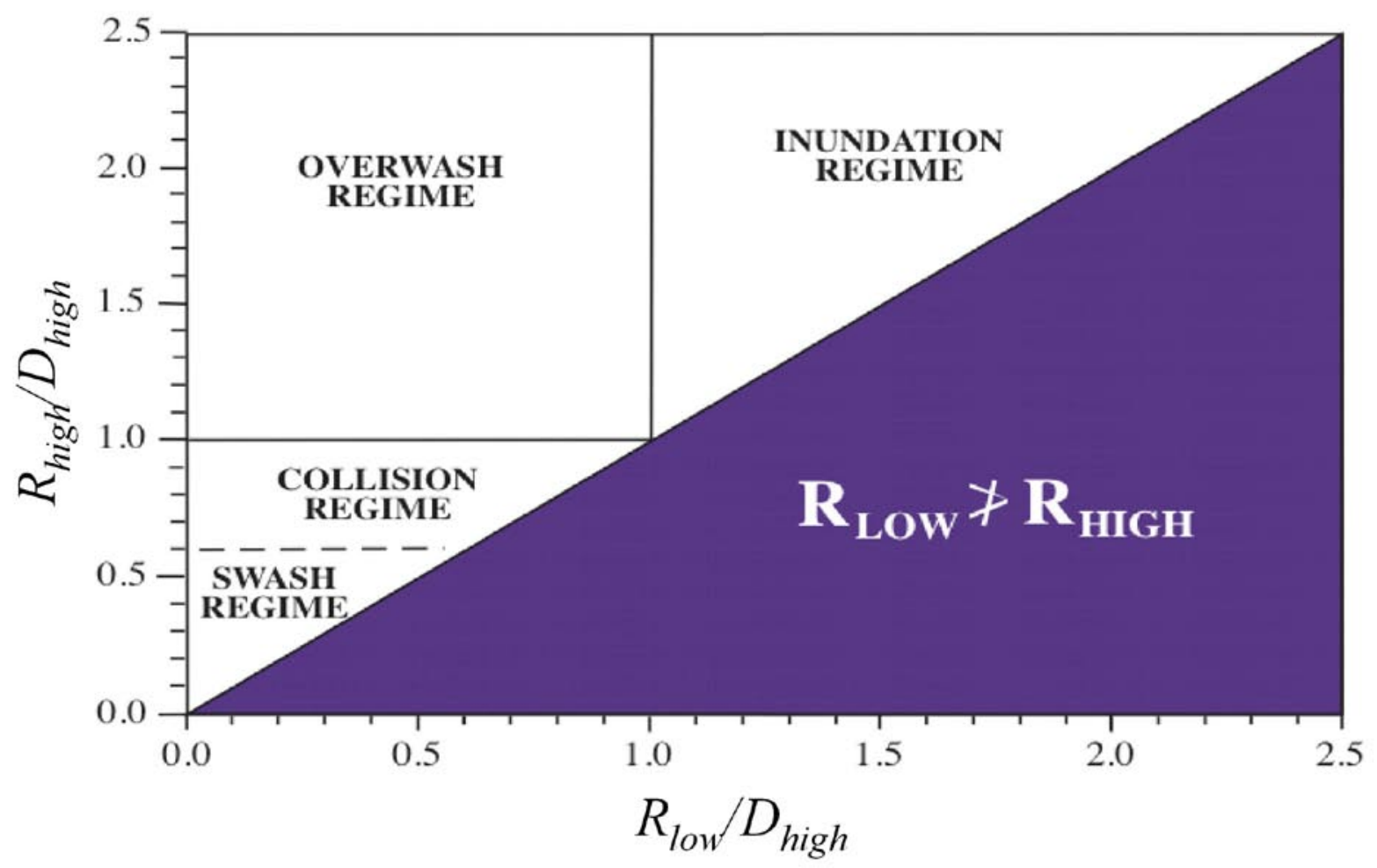

Figure 31. The Sallenger Storm Impact Scale diagram. The $\mathrm{Y}$-axis in the diagram is referred to in the CIAT as X1. The X-axis in the diagram is referred to in the CIAT as X2.

Step Five, and click the Generate Final Impact Assessment button (Figure 38).

Once the Final Impact Assessment file creation is complete, click the Quit button, rename the file, and symbolize the four classes. Included in the Final Impact Assessment menu is a Reclassify into 4 Classes tool. Clicking this tab reclassifies the coastal impact into 4

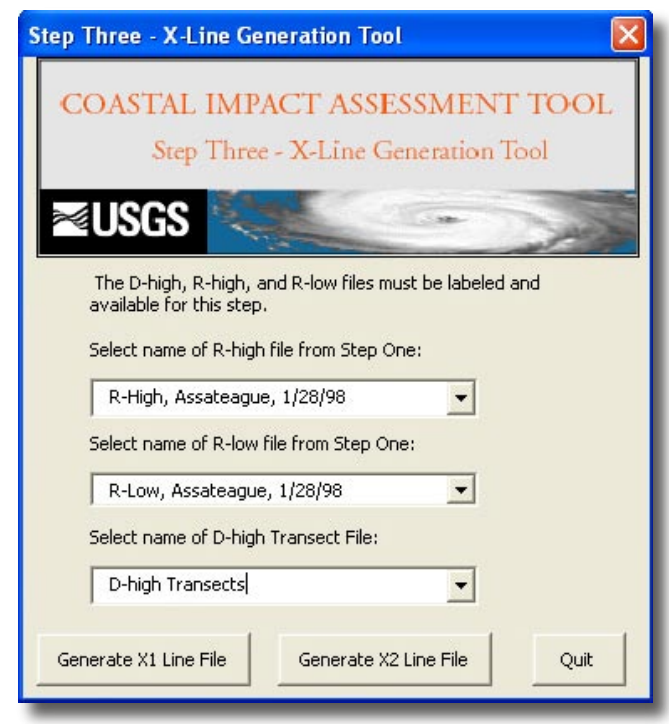

Figure 32. The CIAT Step Three dialog box. classes. The label option allows for the change of the labels on the classes. Simply click the class name under the label tab and change to reflect the appropriate Sallenger Storm-Impact Scale (Figure 39).

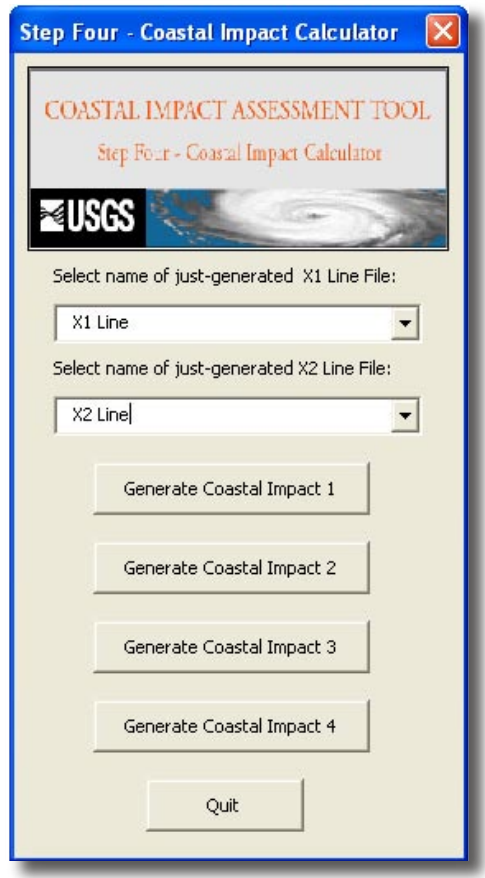

Figure 33. The Coastal Impact Calculator in the CIAT. 


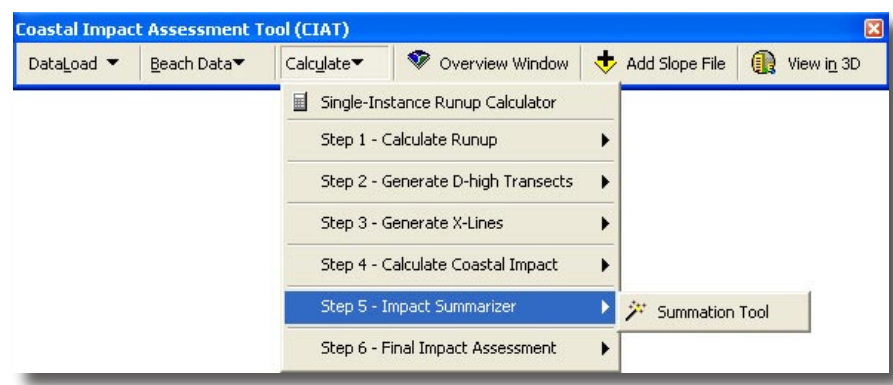

Figure 34. Click the Summation Tool in the CIAT to open the dialog box for Step Five.

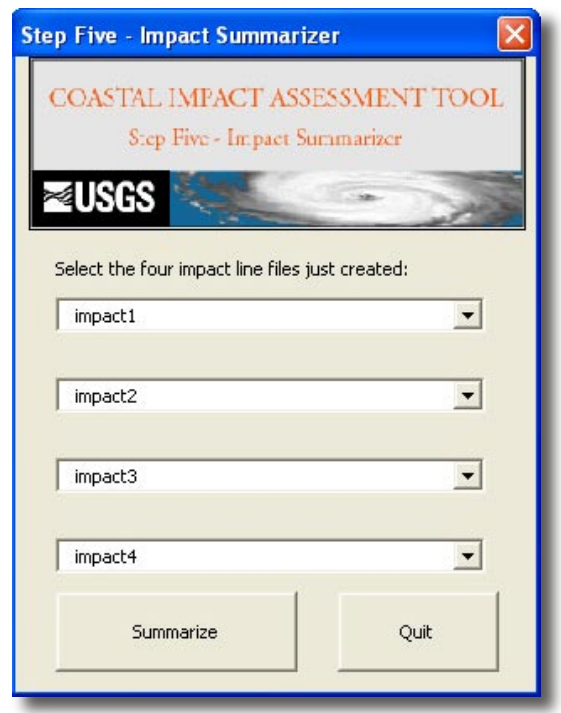

Figure 35. The Impact Summarizer dialog box.

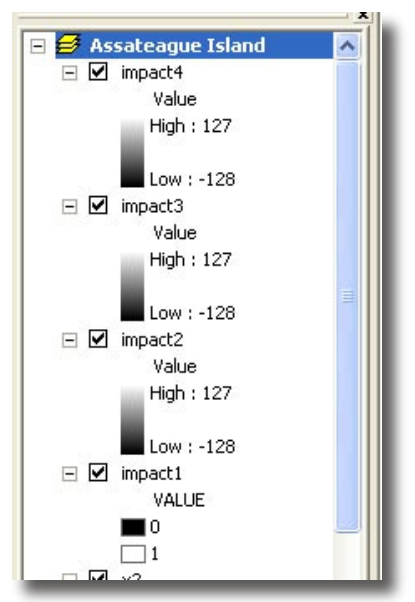

Figure 36 . If raster results appear as values between 127 and -128 , the data have been stretched.

After naming the four classes, the result is a raster file, constrained by the island mask, that indicates the likely coastal impact of a storm based on the parameters input in the R-high and R-low calculator. Based on the preceding example, Figure 40 provides a magnified view

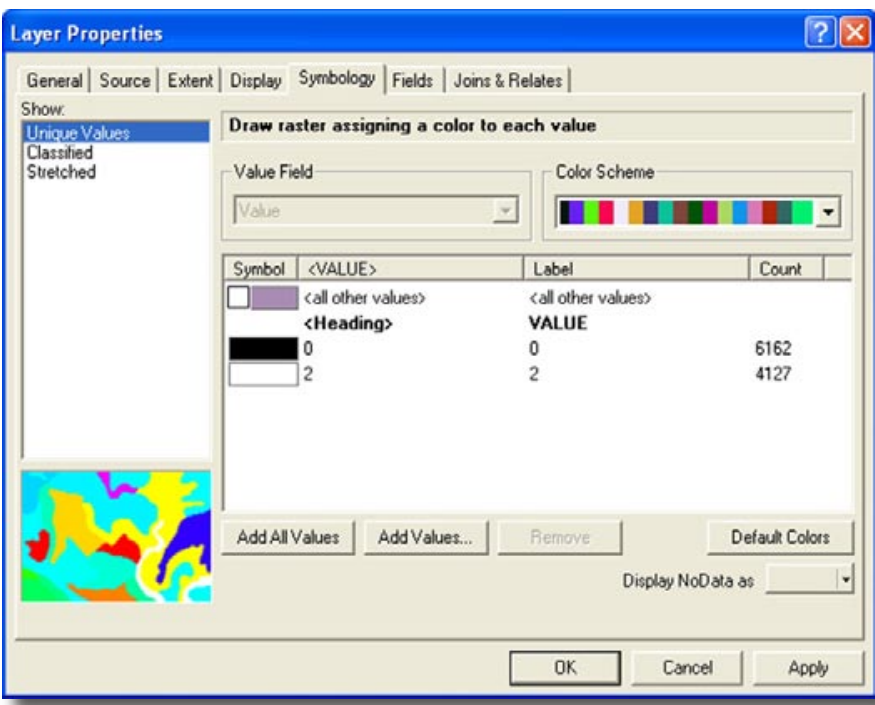

Figure 37. To correct the stretched raster data, open the Layer Properties dialog box, and select Unique Values.

of the CIAT output from a randomly selected location along the Assateague Island shoreline. Note that the results are transect-based within the extent of the ZIC mask.

The different color shades in the legend indicate the different classes of the SSIS. The colors do not have to be red (which is the default color of the automatic reclassifier). The Symbology tab of the Properties dialog box allows for the customization of the colors displayed for the CIAT result. The user should customize these colors to best suit their intended application.

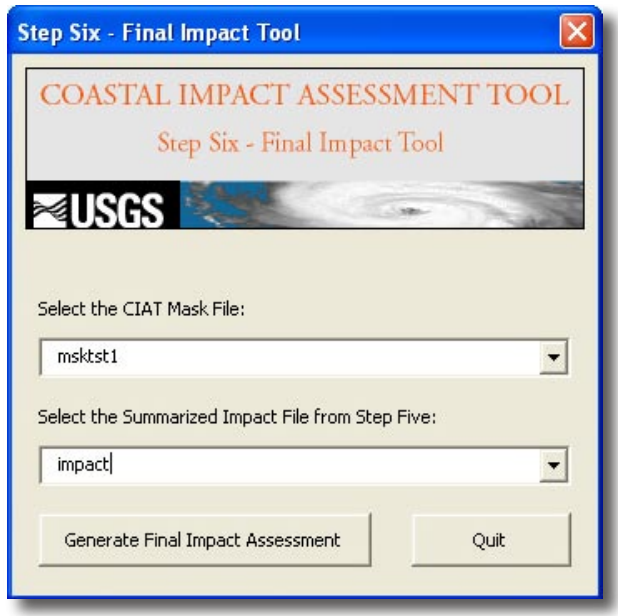

Figure 38. The Final Impact Tool dialog box. 


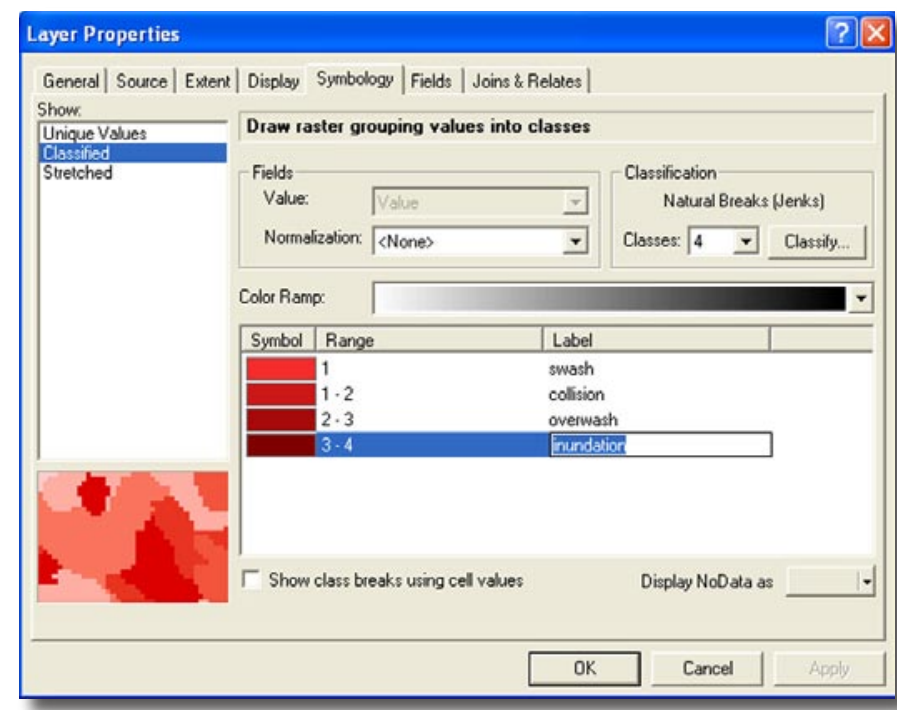

Figure 39. After using the Reclassify tool, change the Label of the values in the Layer Properties dialog box.

\section{Displaying the CIAT Model Results in} 3D

The results of the CIAT model run can be displayed in 3D if the user's computer is equipped with ArcScene. Clicking the rightmost button on the CIAT toolbar, "View in 3D", opens ESRI's ArcScene application.

ArcScene is similar to ArcGIS in layout and method of importing files. However, there are certain distinctions between the two software types. ArcScene requires a layer from which to set the base heights of other layers. Ideally, any area in which the CIAT tool is being applied will have a Digital Elevation Model (DEM) available. If this is not the case, topographic geotiffs or GIS map layers with topographic information can be utilized.

The following example uses the sample CIAT model data pertaining to Assateague Island. To begin, click the aforementioned CIAT toolbar button. ArcScene opens within the ArcGIS window (Figure 41). Using the same Add Data button as in the ArcGIS environment, add the files desired for display into the table of contents.

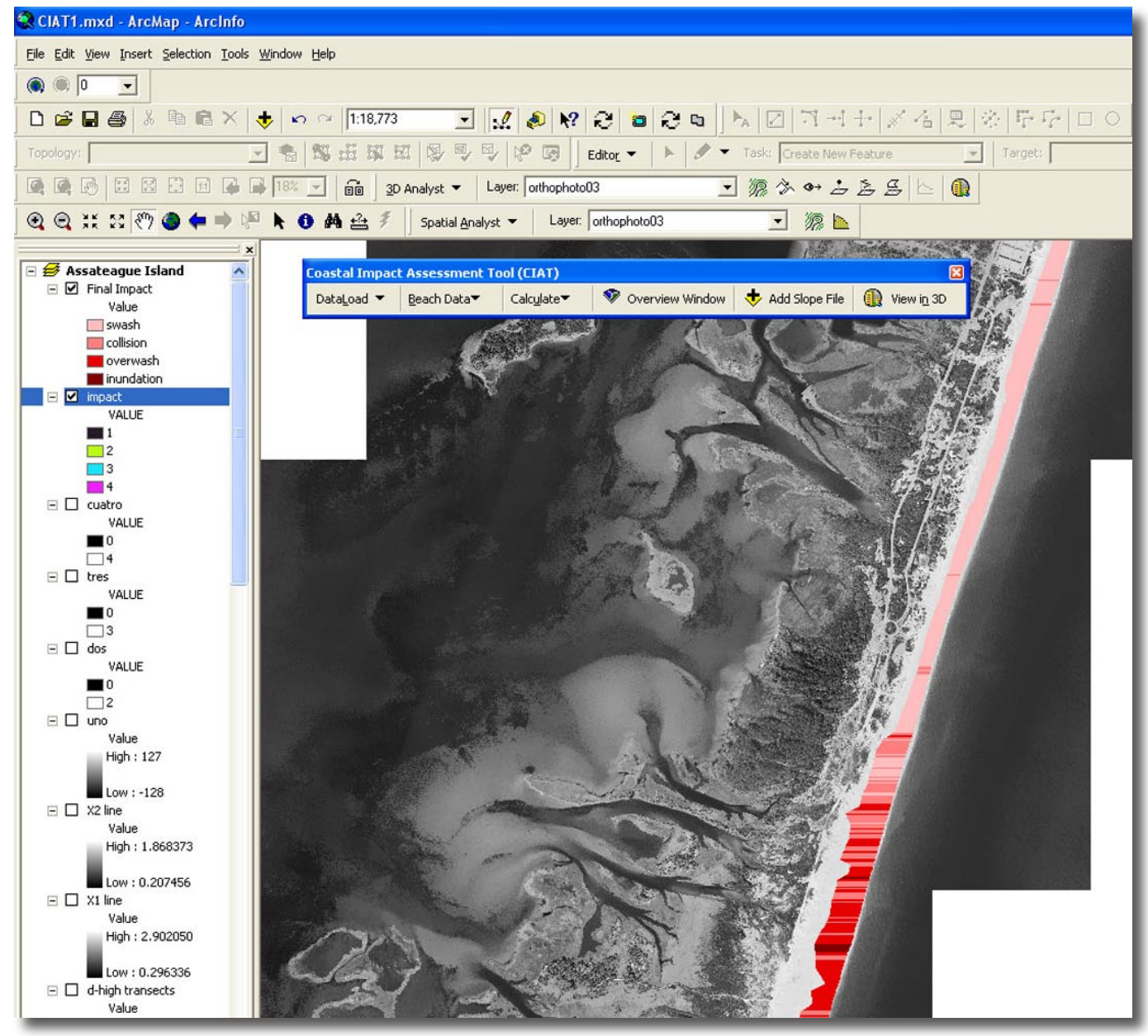

Figure 40. Sample output from the CIAT model run. 
Some rasters may take extra time to load. In addition, all incoming files will be set to the same rendering order. If a layer is obscured by another, reset the rendering order by double-clicking each individual layer and then selecting the Rendering tab. The rendering order is located in the middle of the page and can be used to change the order layers are drawn to allow the desired layer to be located above the others in the display (Figure 42). In addition, in order for the elevations depicted in the image to have demonstrated topography, the base heights of the layers have to be set. In this example, base heights are set to the elevations in a digital elevation model. The baseheight setting procedures can be conducted through the layer properties dialog box for each layer.

Vertical exaggeration is also possible to make layers seem more varied topographically. The vertical exaggera- tion is conducted by double-clicking on the Scene Layers item at the top of the table of contents (Figure 43).

In the following sample illustration (Figure 44), the base heights have been set, and a vertical exaggeration of 2 has been specified. The file created in the CIAT model earlier has been resymbolized and reclassified in ArcScene and named "Coastal Impact." The resolution of each layer can be improved by changing the slider at the bottom of the Rendering tab in the Layer Properties dialog box; however, large or detailed rasters may take a long time to be displayed when the resolution is improved too much. Computing power and capability are the limiting factors to $3 \mathrm{D}$ viewing. For more information on these commands and other procedures available for $3 \mathrm{D}$ viewing purposes, see the Help menu item in ArcScene.

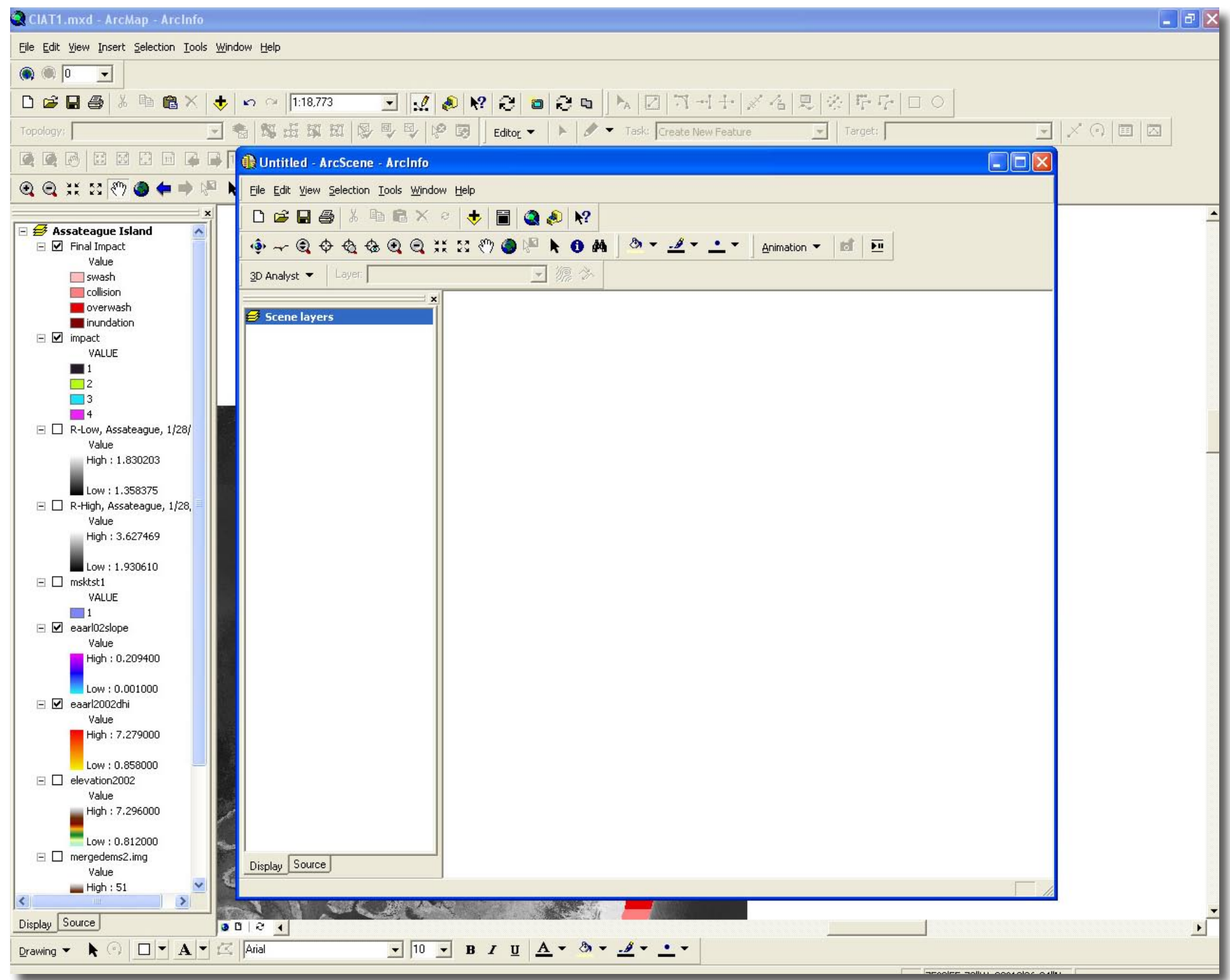

Figure 41. ArcScene open within an ArcMap environment. 


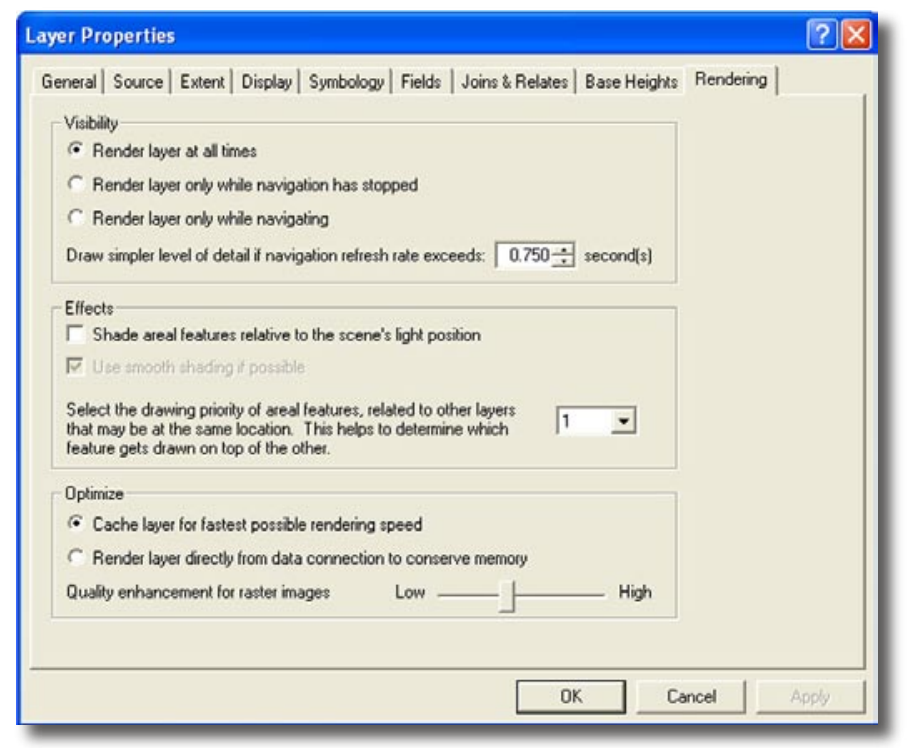

Figure 42. The Rendering tab within a Layer Properties dialog box in ArcScene.

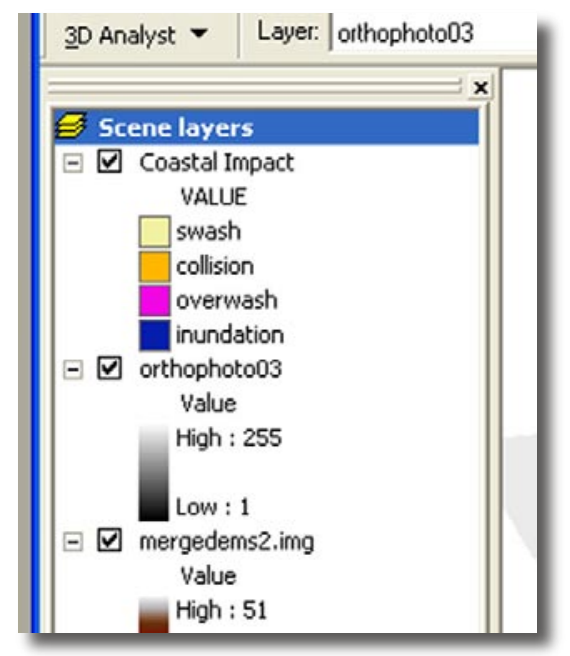

Figure 43. Double-click on Scene Layers in ArcScene to set the vertical exaggeration.

The topography in many ArcScene views will not look dramatic at small scales because much vertical exaggeration will be necessary along a relatively flat coastal region to achieve a dramatic topographic impression. ArcScene capabilities include "fly-overs" of desired terrain and multi-angle/multi-look displays (Figure 45). $3 \mathrm{D}$ viewing is in its early stages of operational feasibility, but the capacity to utilize CIAT output for these purposes has been demonstrated within ArcScene.

\section{A Few Troubleshooting Issues}

Some issues may prevent successful completion or viewing of the CIAT modeling process. D-high and beach slope files are an absolute requirement for operation, as are the parameters for user input. Some potential problems and their solutions are presented here:

1. The final output has gaps in area between transects. To solve this situation, adjust the size of the D-high kernel file as described at the beginning of this document and rerun the model.

2. There is a run-time error message when the CIAT model is run. Sometimes this error can occur when there are too many files in the table of contents. Try removing unnecessary files and then rerun the model.

3. ArcScene crashes upon opening. ArcScene may crash upon initial opening due to computing-power issues. Opening the program a second time usually provides a satisfactory solution.

4. When creating the four coastal impact classes, the data are presented as stretched values between 127 and -128 . Deleting unnecessary or older rasters from the Table of Contents and D:Itemp may help prevent this situation in subsequent model runs.

\section{Summary}

The CIAT is a baseline coastal modeling tool designed to predict the impact from hurricanes and nor' easters to a coastline. It has so far been tested only on Assateague Island, MD/VA, but is designed for use anywhere along the U.S. coastline. Several possible improvements to future CIAT editions should increase the functionality and capability of the model. Suggested improvements to be made in future versions include:

- Improved duration-effect modeling. The CIAT model currently provides a "snapshot," or momentary, prediction of coastal impact. The ability to integrate the effects of any particular storm on a shoreline based on the duration of significant storm effects would greatly enhance the CIAT's capability. Research on storm duration and coastal storm impact is currently underway, but is not yet at a level where it can be incorporated into the CIAT modeling structure.

- Improved directional capability. The current CIAT model uses an assumption of shore-normal wave effects. Future versions should allow for the selection of anticipated wave direction, possibly by 


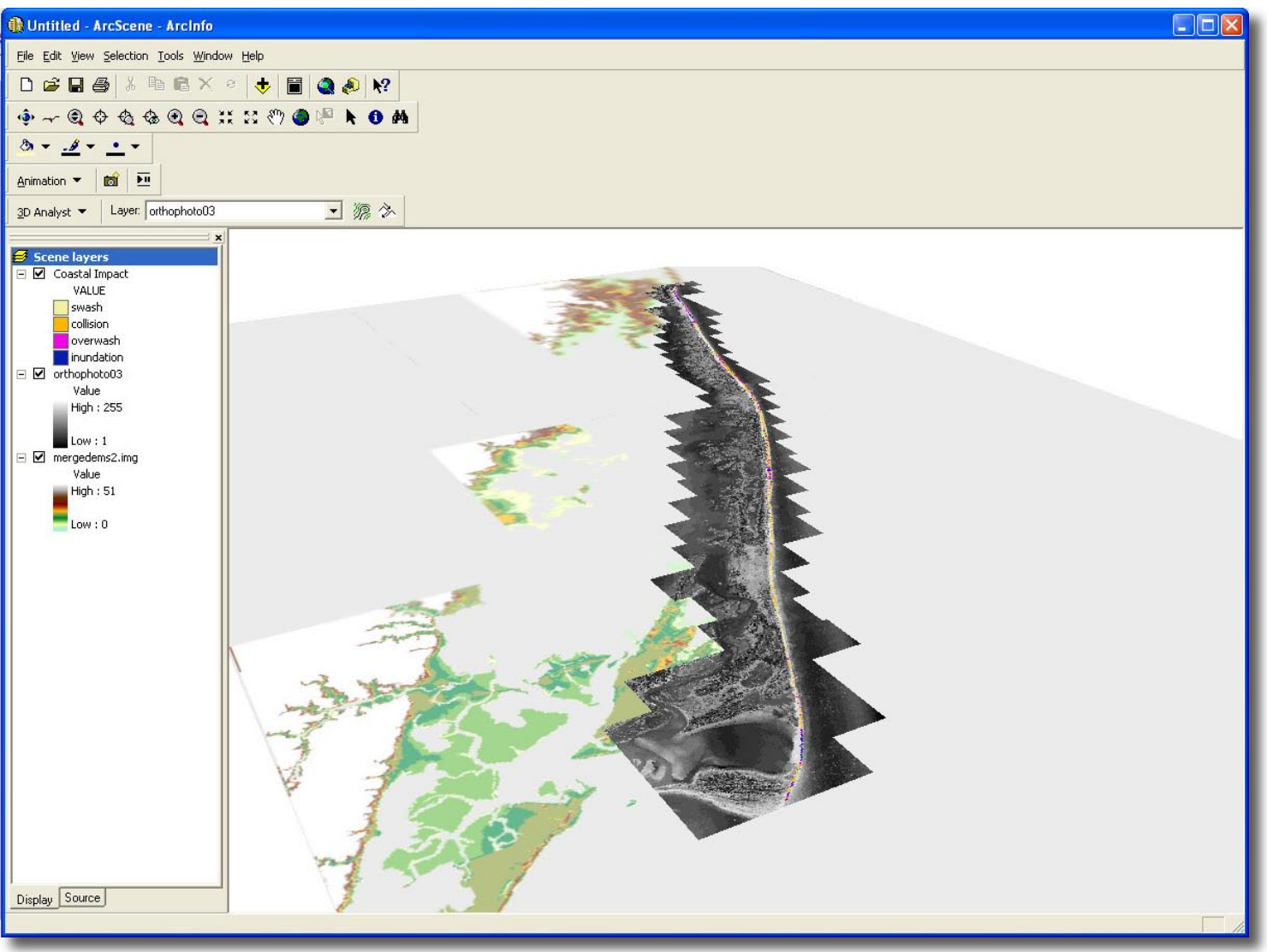

Figure 44. Sample ArcScene display of raster data in 3D.

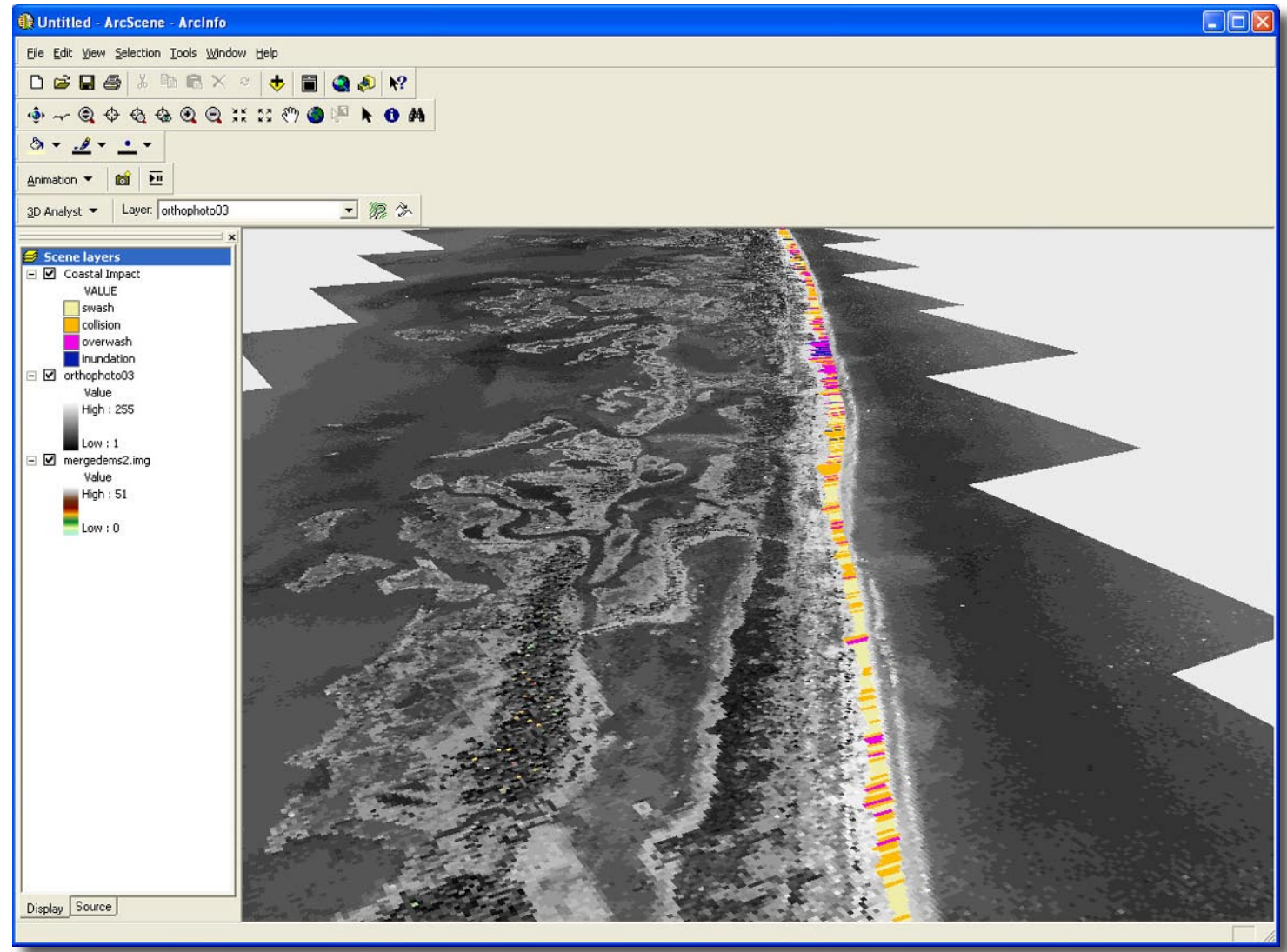

Figure 45. ArcScene allows for multi-angle and "fly-over" display possibilities. 
utilizing "radio" selection buttons and altering the programming model accordingly. More advanced programming techniques will be necessary to achieve this goal, as well as a more sophisticated underlying model for water and sand effects to dunes when wave direction changes during a storm event.

- Automated functions to generate the required baseline files more rapidly. User-processing requirements for the D-high and beach slope files are very time consuming. An automated D-high selection and/or beach slope calculation process would greatly speed up the update-cycle modeling of shorelines in which incoming data are received just prior to a storm event.

- Easier 3D visualization and integration with 3D display programs. While ArcScene provides adequate $3 \mathrm{D}$ visualization capability, it does have some issues with computing-power capacity and speed of display. A more desirable product would be one that integrates with the CIAT and exports active layers automatically and with the appropriate symbolization. Should the CIAT be converted for use with ArcGIS 9.x, the use of ArcGlobe for $3 \mathrm{D}$ visualization should be explored for advantages over ArcScene.

The CIAT has been tested for use on PCs only. The initial version of the CIAT product is Version 1.0 (CIAT v1.0). The CIAT is in a prototype phase. Operational utilization is not anticipated before Version 3.0.

\section{Acknowledgments}

We thank Kristy Guy (USGS) for invaluable assistance during the programming design phase of the CIAT creation process. We also thank Hilary Stockdon (USGS) for assistance with wave runup model improvements, beach slope calculation considerations, and D-high conceptualization. We would additionally like to thank John Brock and Melanie Harris for data assistance. Funding from the USGS Mendenhall Postdoctoral Research Program supported a portion of this research.

\section{References}

Sallenger, A. H., 2000: Storm impact scale for barrier islands. J. Coastal Research, 16, 890-895.

Holman, R. A., 1986: Extreme value statistics for wave runup on a natural beach. Coastal Engineering, 9, 527-544.

Morton, R. A., Guy, K. K., Hill, H. W., and Pascoe, T., 2003: Regional morphological responses to the March 1962 Ash Wednesday storm. Proceedings, Coastal Sediments '03, 11 pp.

Stockdon, H., Holman, R., Howd, P., and Sallenger, A., (In Review): Empirical parameterization of setup, swash, and runup. $42 \mathrm{pp}$. 